JANINE GIUBERTI COUTINHO

PERSPECTIVAS E DESAFIOS DA GOVERNANÇA DA NUTRIÇÃO: DO NÍVEL REGIONAL AO GLOBAL

BRASILIA, 2015 
JANINE GIUBERTI COUTINHO

PERSPECTIVAS E DESAFIOS DA GOVERNANÇA DA NUTRIÇÃO: DO NÍVEL REGIONAL AO GLOBAL

Tese de doutorado apresentada como requisito para o título de Doutor em Nutrição Humana, pelo Programa de Pós-Graduação Em Nutrição Humana, Universidade de Brasília.

Orientadora: Elisabetta Recine

Co-orientadora: Denise Coitinho

BRASILIA, 2015 
JANINE GIUBERTI COUTINHO

\section{PERSPECTIVAS E DESAFIOS DA GOVERNANÇA DA NUTRIÇÃO: DO NÍVEL REGIONAL AO GLOBAL}

Tese de doutorado apresentada como requisito para o título de Doutor em Nutrição Humana, pelo Programa de Pós-Graduação em Nutrição Humana, à seguinte banca examinadora:

Orientadora: Profa. Dra. Elisabetta Recine

Departamento de Nutrição

Universidade de Brasília

Prof. Dra. Renato Maluf

Departamento de Desenvolvimento Agricultura e Sociedade

Universidade Federal Rural do Rio de Janeiro

Prof. Dra. Ximena Pamela Bermudez

Departamento de Saúde Coletiva

Universidade de Brasília

Profa. Dra. Juliana Rochet

Faculdade UnB Planaltina - Área de Ciências Humanas e Sociais

Universidade de Brasília

Profa. Dra. Renata Monteiro

Departamento de Nutrição

Universidade de Brasília

Nathalie Beghin

Coordenadora da Assessoria Política

Instituto de Estudos Socioeconômicos 


\section{Agradecimentos}

À Betta,

Pela inspiração, incentivo constante, por confiar em mim. Obrigada de coração!

À Denise,

Pela orientação, incentivo, e "puxões de orelha"...

À Pamela,

Pelo carinho e atenção em qualquer momento.

À Patrícia e à Michele,

Pela amizade e palavras e incentivos constantes.

A toda equipe da Coordenação-Geral de Educação Alimentar e Nutricional, especialmente Luisete, que "segurou as pontas" nas minhas ausências...

Aos meus amigos,

Pela animação, incentivo e paciência...

Minha querida e amada família, minhas irmãzinhas e especialmente papai e mamãe, Vocês são meu porto seguro, meu norte. Sem vocês não seria possível!

Ao Bruno, Pela paciência, pelo apoio na reta final.

E, especialmente, aos meus filhotes, Dudu e Rafa, Vocês são minha inspiração, meus amores! 


\section{Sumário}

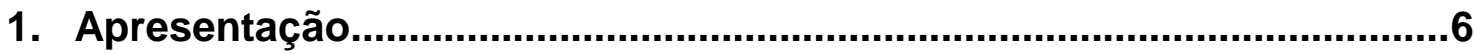

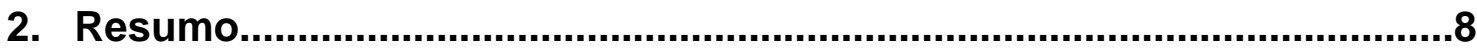

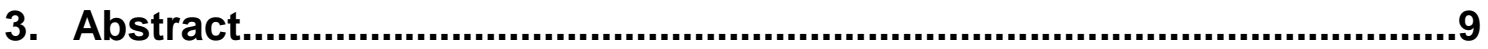

4. Introdução

4.1. Múltipla carga da má nutrição e seus determinantes ...........10

4.2. A promoção e proteção do Direito Humano à Alimentação Adequada e Saudável e o alcance da Soberania Alimentar dos países para o enfrentamento dos determinantes da múltipla carga da má nutrição................................................11

4.3. Governança Global em Nutrição ancorando o enfrentamento das múltiplas cargas da má nutrição .....................................13

4.4. Breve histórico dos arranjos institucionais globais da

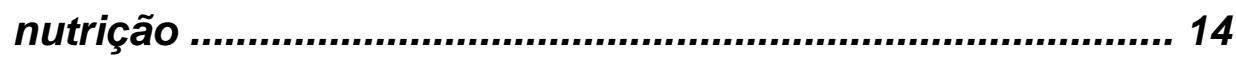

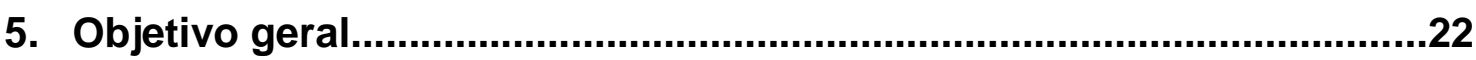

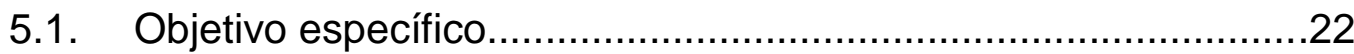

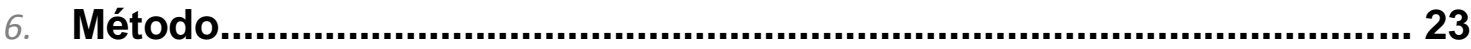

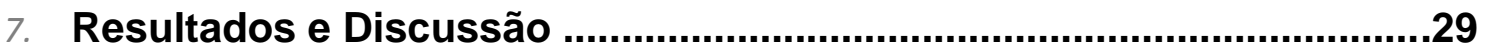

Artigo 1: $O$ enfrentamento da má nutrição no nível global: uma análise dos pronunciamentos dos países na Segunda Conferência Internacional de Nutrição (ICN2) ${ }^{1}$

Artigo 2: Potentials and challenges for a common market put forward the nutritional agenda: the case of Mercosul ${ }^{2}$. 60

Artigo 3: $O$ enfrentamento do sobrepeso e obesidade segundo a percepção dos pontos focais de nutrição de países integrantes do Mercosul: ${ }^{3}$ .79

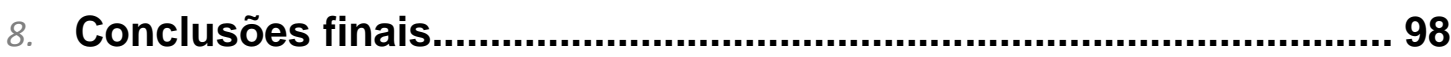

9. Referências Bibliográficas.................................................................102

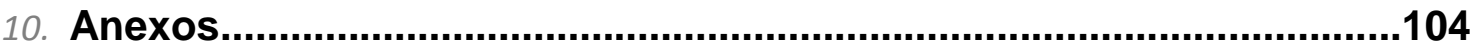

\footnotetext{
${ }_{2}^{1}$ Artigo a ser traduzido para o inglês e ser submetido para a revista Public Health Nutrition.

2 Artigo submetido a revista Panamericana de Salud Pública/Pan American Journal of Public Health.

${ }^{3}$ Artigo a ser submetido para a revista Panamericana de Salud Pública/Pan American Journal of Public Health.
} 


\section{Apresentação}

Diante da múltipla e elevada carga de má nutrição que acomete as populações do mundo e considerando a necessidade dos países responderem aos problemas nutricionais com mais assertividade e rapidez, o presente estudo visou explorar possibilidades no âmbito da governança da nutrição, do nível global ao nível sub-regional, para melhor estruturação da resposta dos países à má nutrição.

Este documento intitulado "Perspectivas e desafios da governança da nutrição: do nível regional ao global' está organizado em oito capítulos, como detalhado no sumário. A caracterização da múltipla carga da má nutrição no mundo e um breve histórico dos arranjos institucionais globais de governança da nutrição tecem o pano de fundo do estudo e compõem a introdução deste documento que segue com objetivos geral e específicos.

A complexidade do objeto de pesquisa determinou o seu escopo e definiu a necessidade de se explorar o tema tanto sob um olhar de abrangência global, como sub-regional. Nesta perspectiva, o quinto capítulo da tese, relativo à descrição do método empregado no estudo, apresenta a abordagem, técnicas utilizadas para captar manifestações e percepções dos diferentes atores, bem como subsidiar análises documentais.

A escolha do objeto de pesquisa foi em função do interesse por estudar no campo da nutrição as relações de cooperação internacional entre os países, as agências das Nações Unidas e outros parceiros afetos ao tema, e de como se situam, sua estrutura de forças, interesses em diferentes espaços políticos nos níveis nacional, sub-regional, regional e global.

Este interesse foi fortalecido em função da minha trajetória profissional. Primeiro enquanto técnica no Ministério da Saúde, e em sequência na posição de consultora nacional na Organização Pan-americana de Saúde/Organização Mundial da Saúde no Brasil. Em ambos os espaços institucionais, mas em posições diferentes, tive a oportunidade de aprender e tratar do tema da nutrição no campo internacional tanto na sua esfera sub-regional, participando do Grupo de Trabalho de Segurança Alimentar e Nutricional do Mercosul, como 
também na esfera global participando de algumas reuniões relevantes a exemplo de reuniões anuais do Comitê Permanente de Nutrição da ONU (SCN) o que em alguma medida me trouxe interesse no tema.

Os resultados e discussão deste estudo exploratório estão apresentados na forma de três manuscritos, que respondem aos três objetivos específicos da tese. O primeiro explora as formas como os países participantes de uma importante conferência internacional de nutrição, a ICN2, percebem os problemas nutricionais, suas soluções e as articulações e parcerias necessárias. Os outros dois artigos trazem o olhar para o nível sub-regional a partir do caso específico do Mercosul. O presente documento é finalizado com conclusões finais. 


\section{Resumo}

Nos dias atuais, as populações do mundo padecem de múltiplas formas de má nutrição que expressam violações ao direito humano à alimentação adequada e saudável e tem entre suas causas, a configuração dos sistemas alimentares dos países. É urgente uma resposta global mais rápida e assertiva que se dirija não apenas para o tratamento da má nutrição, mas, sobretudo, para o equacionamento de seus determinantes. Para isto é fundamental ter-se uma governança global da nutrição, ou seja, um arcabouço de interação e engajamento de atores e instituições no âmbito global coordenados com os níveis regionais e nacionais que abarque e possa influenciar múltiplos setores. Este trabalho visou identificar perspectivas e desafios da estruturação de processos para o enfrentamento da má nutrição do nível sub-regional ao global. Foi um estudo de natureza qualitativa realizado em três etapas. A primeira exploratória e descritiva, de base documental. O segundo momento uma análise documental sobre as estruturas e instâncias de trabalho no Mercosul. E, a última explorou a percepção de pontos focais de nutrição no Mercosul quanto à compreensão e incorporação da obesidade nas suas agendas políticas, bem como o papel do Mercosul para o combate a obesidade. Os países estão, em maior ou em menor grau, programando-se e enfrentando a má nutrição embora com reconhecimento apenas parcial da sua determinação. Para isto é necessário o enfrentamento com os interesses econômicos das indústrias de alimentos transnacionais que estão no centro do processo de determinação da forma como as populações do mundo se alimentam atualmente. Para o remodelamento estrutural dos sistemas alimentares, faz-se necessário um conjunto de medidas, entre as quais assumem particular importância aquelas voltadas à regulação de mercado. O olhar para o Mercosul ilustrou reflexões sobre caminhos a serem trilhados para a governança global para nutrição em espaços sub-regionais. São espaços que precisam priorizar a saúde e a promoção da alimentação saudável por meio de medidas como o estabelecimento de regras sanitárias que não respondam somente à segurança do alimento do ponto de vista biológico, mas também no ponto de vista da qualidade nutricional. Em nível regional, os países que compõe blocos comerciais, como o Mercosul, caso articulados em torno de uma mesma agenda e prioridades, podem vir a tornar-se atores estratégicos nestes espaços globais, com vistas a impulsionarem temas que coloquem a saúde e a promoção da alimentação adequada e saudável. Estes avanços observados no âmbito do Mercosul, mesmo que modestos, podem ser considerados como um acúmulo que, a médio prazo, poderá criar as condições necessárias para que medidas mais complexas, como a regulação de mercado, sejam efetivamente implementadas sob a égide da proteção e a promoção da alimentação adequada e saudável. As perspectivas e desafios para a estruturação de processos ágeis e assertivos devem considerar, em primeiro lugar, a determinação dos problemas nutricionais. $A$ "agenda de futuro" está na implementação de medidas de regulação de mercado para o efetivo remodelamento dos sistemas alimentares com o aproveitamento dos espaços regionais e globais para fortalecer movimentos e posicionamentos de países. Os blocos comerciais regionais podem ser espaços estratégicos para a tomada de posições conjuntas em espaços de negociação global. 


\section{Abstract}

Nowadays, the population of the world suffers from multiple forms of malnutrition expressing violations of the human right to adequate and healthy food and has among its causes, the configuration of the food systems of the countries. It is urgent an assertive global response to address not only the treatment of malnutrition, but also solution of its determinants. It's essential a global governance of nutrition, ie a framework of interaction and engagement of actors and institutions globally coordinated with the regional and national levels. This study aimed to identify prospects and challenges of structuring processes to combat the malnutrition of the sub-regional globally. It was a qualitative study carried out in three steps. The first exploratory and descriptive, document basis. The second time a documental analysis of the structures and working bodies in Mercosur. And, the last explored the perception of nutrition focal points in Mercosur as the understanding and incorporation of obesity in their political agendas as well as the role of Mercosur to combat obesity. Countries are addressing malnutrition although with only partial recognition of their determination. This requires coping with the economic interests of transnational food industries at the heart of the process of determining how populations of the world are currently feed. For the structural remodeling of food systems, it is necessary a series of measures, among which are of particular importance those related to market regulation. The Mercosur illustrated reflections on ways to be followed for global governance for nutrition in subregional areas. There are spaces that need to prioritize health and promoting healthy eating through measures such as establishing health conditions that do not respond only to the safety of food from a biological point of view, but also from the viewpoint of nutritional quality. At the regional level, the countries that make up trade blocs, such as Mercosur, if articulated around a common agenda and priorities, are likely to become strategic players in these global spaces in order to push forward issues that put the health and promotion proper and healthy eating. These advances made within Mercosur, even if modest, can be considered as an accumulation that in the medium term, can create the conditions necessary for more complex measures such as market regulation, are effectively implemented under the umbrella of protection and promoting adequate and healthy food. Prospects and challenges for structuring agile and assertive processes should consider, first, the determination of nutritional problems. The "future agenda" is the implementation of market regulation measures for the effective remodeling of food systems with the use of regional and global spaces to strengthen movements and positions of countries. Regional trade blocs can be strategic spaces for taking joint positions in the global trading spaces. 


\section{Introdução}

\section{Múltipla carga da má nutrição e seus determinantes}

Nos dias atuais, as populações do mundo padecem de múltiplas formas de má nutrição ${ }^{4}$. A desnutrição infantil, na sua forma crônica ${ }^{5}$, afeta em torno de 161 milhões de crianças menores de cinco anos no mundo. A subnutrição é ainda, a mais importante causa de morte de crianças dessa faixa etária, tendo sido, em 2013, responsável por $45 \%$ da mortalidade neste grupo. Quanto às deficiências por micronutrientes estima-se que acometam atualmente mais de dois bilhões de pessoas (FAO/OMS, 2014).

Ao mesmo tempo, na outra face da insegurança alimentar e nutricional, estão o excesso de peso e a obesidade, que têm aumentado globalmente. Cerca de 42 milhões de crianças menores de cinco anos já eram afetadas pelo excesso de peso em 2013 e mais de 500 milhões de adultos eram obesos em 2010 (FAO/OMS, 2014). O sobrepeso e a obesidade, além de serem problemas de saúde em si, são também fatores de risco para outras inúmeras doenças, representando uma grande carga social e sobrecarga para os serviços de saúde dos países.

O sistema alimentar nunca esteve tão concentrado e controlado por tão poucos: os treze maiores conglomerados industriais de alimentos do mundo ${ }^{6}$ detém $26 \%$ do mercado global e 100 cadeias de venda direta ao consumidor controlam 40\% do comércio varejista de alimentos (RIBEIRO, 2008). Dada esta concentração de poder econômico e, consequentemente, político, muitas vezes são as empresas transnacionais e não os governos dos países que definem e implementam as macropolíticas estratégicas de abastecimento alimentar (STEDILE \& CARVALHO, 2012).

\footnotetext{
${ }^{4}$ A má nutrição é um termo amplo utilizado como alternativo para a desnutrição. Mas, tecnicamente, também se refere a uma situação de excesso de calorias (UNICEF, 2015).

5 A desnutrição crônica é aferida pelo indicador de déficit de altura/estatura por idade (Mercedes de Onis et al, 2012).

${ }^{6}$ Nestlé, Monsanto, Bungue, Dreyfuss, Kraft Foods, Pepsi-cola, Coca Cola, Unilever, Tyson Foods, Cargill, Marte, ADM, Danone.
} 
Todos estes desfechos nutricionais desfavoráveis, caracterizados pela condição de má nutrição, expressam violações ao direito humano à alimentação adequada e saudável e tem entre suas causas, a configuração dos sistemas alimentares dos países. Isto é, a forma como são produzidos, processados, comercializados e consumidos os alimentos. Consequentemente, estes desfechos são, em última análise, também responsabilidade dos atores que controlam esses sistemas alimentares (STEDILE \& CARVALHO, 2012; STUCKLER \& NESTLE, 2012; OPAS, 2015).

Diante deste cenário, é urgente uma resposta global mais rápida e assertiva que se dirija não apenas para o tratamento das diferentes formas da má nutrição, mas, sobretudo, para o equacionamento de seus determinantes com vistas à proteção do direito humano à alimentação adequada (DHAA) para as populações do mundo e garantia da soberania alimentar dos países.

\section{A promoção e proteção do Direito Humano à Alimentação Adequada e Saudável e o alcance da Soberania Alimentar dos países para 0 enfrentamento dos determinantes da múltipla carga da má nutrição}

A promoção e a proteção do direito humano à alimentação adequada é parte dos direitos fundamentais da humanidade. Segundo a Declaração Universal de Direitos Humanos, que foi adotada e proclamada pela Assembleia Geral das Nações Unidades em 1948, "toda pessoa tem direito a um padrão de vida capaz de assegurar a si e sua família saúde e bem estar, inclusive alimentação..." (ONU, 1948).

Outro Pacto Internacional de relevância foi o dos Direitos Econômicos, Sociais e Culturais (PIDESC). Este teve início em 1951 e também foi adotado pela Assembleia Geral das Nações Unidas dezoito anos após a Declaração Universal dos Direitos Humanos. Seus avanços se pautaram no reconhecimento do papel do Estado para o alcance do direito de toda a pessoa à alimentação e adoção de medidas de cooperação internacional para melhorar os métodos de produção, conservação e distribuição de gêneros alimentícios e 
também assegurar uma divisão equitativa de recursos alimentícios mundiais em relação às necessidades (ONU, 2012).

Mais recentemente, as Diretrizes Voluntárias para o DHAA elaborado em 2004 sob a liderança da Organização das Nações Unidas para a Alimentação e Agricultura (FAO) fez a relação entre a realização dos direitos humanos e efetivação de programas e políticas de diversas áreas.

No âmbito do Conselho de Direitos Humanos das Nações Unidas ${ }^{7}$, há uma posição de Relator Especial ocupada por um especialista no tema. Segundo o Relator Especial e os Acordos Internacionais pactuados ao longo dos anos desde a Declaração Universal de Direitos Humanos, o direito à alimentação é o direito de ter acesso regular, permanente e irrestrito, seja diretamente ou por meio de aquisições financeiras, para quantitativamente e comida qualitativamente suficiente e correspondendo às tradições culturais do povo a que o consumidor pertence, e que garantem uma vida física e mental, individual e coletiva, digna e livre do medo (ONU, 2015). Isto é, o DHAA deve ser interpretado em um sentido mais amplo da alimentação e não somente no escopo do acesso de nutrientes (calorias, proteínas e outros), mas deve ser considerada a dimensão de aspectos que promovem e protegem a alimentação saudável.

Já, o conceito da soberania alimentar preconiza a produção dos alimentos pela agricultura familiar e agricultura camponesa como centro dos sistemas alimentares, no lugar das grandes corporações, com vistas à maior sustentabilidade ambiental, econômica e social. Preconiza práticas de produção e comercialização justas e transparentes. Além da regulação de mercado, de modo a garantir o direito dos consumidores de controlarem sua alimentação e a assegurar o direito ao uso da terra e território, água, sementes e da biodiversidade (NYELENI, 2007; RIBEIRO, 2013).

\footnotetext{
${ }^{7}$ O Conselho substituiu a Comissão das Nações Unidas sobre Direitos Humanos desde 2006 (http://www.ohchr.org/en/hrbodies/hrc/pages/hrcindex.aspx).
} 


\section{Governança Global em Nutrição ancorando o enfrentamento das múltiplas cargas da má nutrição}

Governança é um tema de estudo do Banco Mundial. MALDONADO (2010) apresenta uma análise do conceito de governança realizado por esta instituição. Este emergiu no final dos anos oitenta com a realização de estudos em diferentes continentes e países com o foco em explorar a necessidade de uma reforma para um setor público mais eficiente.

$\mathrm{Na}$ esfera nacional e com o foco no aprimoramento da gestão pública, a definição de governança foi tratada como "o exercício da força política para gerenciar temas das nações". Mais tarde, o conceito foi aprimorado e publicado em um documento o qual trazia a relação entre governança e desenvolvimento. Neste documento, governança foi definida como "a maneira na qual a força é exercida para a gestão de recursos sociais e econômicos para o desenvolvimento".

Já no âmbito global, HURRELL conceitua governança considerando seus múltiplos níveis, arenas e atores envolvidos ao invés da lógica de uma centralização e governos globais. Segundo ele, a governança diz respeito à criação e o funcionamento de instituições sociais que servem para definir práticas sociais, designar papéis e orientar as interações entre os que os desempenham com vistas a solucionar conflitos, facilitando cooperação, ou mais aliviando os problemas de ação coletiva em um mundo constituído por atores independentes.

Trazendo a compreensão de governança global para o campo da nutrição com o intuito de favorecer uma ação coordenada e assertiva para o enfrentamento das múltiplas cargas da má nutrição, entende-se que alguns aspectos precisam ser observados.

O primeiro é que para uma governança global da nutrição é fundamental incluir, engajar não somente um setor. Mas, todos os setores afetos ao tema como agricultura, saúde, meio ambiente, comércio, desenvolvimento, proteção social e direitos humanos considerando a natureza multisetorial da nutrição. E, para que de fato seja um processo de governança 
esta relação precisa estar construída em um arcabouço de interação e engajamento de atores e instituições representantes dos temas afetos em âmbito global coordenados com os níveis regionais e nacionais.

Um segundo aspecto é a participação, interação entre estes atores e instituições. É imperioso favorecer a participação legítima de grupos e populações afetadas pelos determinantes da má nutrição. Estes representados pela sociedade civil organizada e movimentos sociais, privilegiando que na estrutura do processo de decisório não sejam perpetuadas as desiguais relações de poder existentes.

E, por fim, estruturas de governança nas quais os governos sejam protagonistas dos processos de decisão e que o espaço político seja protegido de conflitos de interesse (COITINHO \& MAHY, 2014; FAO, OMS, 2014; RECINE \& BEGHIN, 2014).

Como em todo processo político, a idealização e a implementação de políticas de nutrição no âmbito nacional e internacional, principalmente no que concerne ao sistema alimentar, são frequentemente balizadas e induzidas pela estrutura de forças e interesses de diferentes grupos.

\section{Breve histórico dos arranjos institucionais globais da nutrição}

Com o fim da Segunda Guerra Mundial (1945), e com a então recémcriada Organização das Nações Unidas (ONU), o presidente dos Estados Unidos, Franklin Roosevelt reuniu 44 governos, a partir da convocatória de que havia fome em muitos países do mundo enquanto em outros, prevalecia os excedentes de alimentos. Esta reunião representou o nascimento da Organização das Nações Unidas para Alimentação e Agricultura - FAO (CHONCHOL, 2005) com a missão de "alcançar segurança alimentar a partir do acesso regular a alimentos suficientes e de alta qualidade para que as pessoas tenham uma vida saudável' (FAO, 2015). 
Três anos depois foi criada a Organização Mundial da Saúde (OMS), com a missão de liderar a promoção e proteção da saúde pública em nível global (OMS, 2015). Em função da experiência prévia de elaboração de um documento sobre necessidades nutricionais em 1936, no âmbito da Liga das Nações $^{8}$, a FAO e a OMS estabeleceram um mecanismo de coordenação em nutrição, denominado Comitê de Especialistas em Nutrição (Expert Committee on Nutrition) FAO/WHO (CHONCHOL, 2005).

Apesar de reestruturações institucionais, compromissos e iniciativas, a fome continuou sendo um problema mundial crescente. Em 1974, a FAO convocou a World Food Conference ${ }^{9}$, para tratar do tema. Nesta, os países participantes requisitaram que o Conselho Econômico e Social das Nações Unidas $(\mathrm{ECOSOC})^{10}$ considerasse a necessidade da criação, no bojo do Sistema das Nações Unidas, de uma instância de governança que pudesse dar seguimento aos acordos da Conferência (ECOSOC, 1976).

Em 1977, o ECOSOC, reconhecendo que as decisões políticas no campo da nutrição eram prerrogativas dos governos e a importância de uma ação coordenada de nutrição no âmbito das Nações Unidas, orientou a criação de um grupo com as representações de agências afetas ao tema. Este comitê foi concebido para ser um ponto de convergência e harmonização de políticas e atividades do sistema ONU. Assim foi criado o Comitê Permanente da Nutrição da ONU - SCN (ECOSOC, 1977), com mandato para promover cooperação entre as agências da ONU e organizações parceiras ao apoio comunitário, nacional, regional e internacional para eliminação da má nutrição em todas as suas formas (SCN, 2015).

Esta instância passou por uma série de mudanças ao longo dos últimos trinta anos. Richard Longhurst (2010) detalhou a evolução histórica do SCN que preencheu, mesmo de que forma incompleta, um papel na governança global da nutrição ao longo da sua existência.

\footnotetext{
${ }^{8}$ A Liga das Nações ou Sociedade das Nações foi uma organização internacional idealizada em Paris onde as potências vencedoras da Primeira Guerra Mundial se reuniram para negociar um acordo de paz. Foi extinta por volta de 1942. Teve suas responsabilidades substituídas pela Organização das Nações Unidas (ONU).

${ }^{9}$ Conferência realizada em Roma. Nesta os países se comprometeram a eliminar a fome em 10 anos, por meio da Declaração Universal para a Erradicação da Fome e má-nutrição.

${ }^{10}$ Plataforma das Nações Unidas para questões econômicas e sociais (www.un.org/en/ecosoc/index).
} 
Segundo Longhurst (2010), o SCN passou por três eras. Na primeira, entre 1977 e 1985, sua estrutura organizacional foi de um triunvirato formado pelas agências da $\mathrm{ONU}$, por um grupo consultor de nutrição, denominado "Advisor Group on Nutrition - AGN" e por um conjunto de países doadores. Este período foi marcado pelo início da parceria com países doadores e também por um conjunto de recomendações de intervenções nutricionais voltadas, por exemplo, à orientação do aleitamento materno e alimentação complementar; controle de deficiências de vitamina A e iodo.

A segunda fase relatada por Longhusrt, de 1985 a 1990, foi marcada pela participação crescente de múltiplos atores nas reuniões do SCN, pelo bom desempenho do grupo consultor (AGN), a boa articulação das agências em torno da agenda de nutrição e, por fim, pelo comprometimento dos países doadores.

Contudo, havia a expectativa de que este Comitê desempenhasse um papel mais proativo. Nesse período o SCN liderou a sistematização de informações da situação de nutrição no nível global, elaborando diversas edições do World Nutrition Report. Foi também neste período que uma série de conferências globais com relevância para a nutrição foram promovidas sob o protagonismo das Nações Unidas como o "World Summit for Children, 1990"; "Ending Hidden Hunger, 1991"; "International Conference on Nutrition (ICN), 1992"; "World Summit for Social Development, 1995"; "World Food Summit, 1996" (Longhurst, 2010). A ICN representou, particularmente, um marco importante para a nutrição mundial uma vez que promoveu a elaboração de Planos Nacionais de Ação para a Nutrição os quais definiam prioridades e estratégias dos países para o enfrentamento da fome e má nutrição. Estes planos serviram também como estratégia de mobilização política e de apoio financeiro para programas de nutrição (COITINHO \& MAHY, 2014).

A terceira e última fase identificada por Longhurst, que compreende 0 período entre 1990 a 2008, foi caracterizada pela realização de um planejamento estratégico do SCN, o qual foi aprovado pela plenária de sua $27^{\text {a }}$ Sessão anual, em 2000, em Washington, DC, EUA. 
Outros marcos importantes durante estes dezoito anos foram: a inserção da sociedade civil organizada e organizações não governamentais na estrutura de participação do SCN; criação de Grupos de Trabalho, os quais em alguma medida substituíram o AGN; e a redefinição da participação dos países na estrutura de governança. Até então, os países representados eram somente os doadores. A partir da aprovação da proposta de planejamento, estavam representados tanto países doadores quanto "receptores". De acordo com Valente, neste período o SCN desempenhou o papel de promoção da articulação das iniciativas de agências intergovernamentais e, também, de articulação com a sociedade civil (VALENTE, 2015),

Ao final do terceiro período, novos doadores entram no cenário global da nutrição, a exemplo da Fundação Bill e Melinda Gates (FBMG). A Fundação financiou uma série de artigos científicos publicados pela revista Lancet sobre "Maternal and Child Undernutrition" em 2008 ${ }^{11}$, que deu uma grande visibilidade à agenda da nutrição em nível global. Um dos artigos desta edição fez duras criticas à fragmentação e disfuncionalidade do sistema de governança global para a nutrição, destacando a necessidade urgente de uma reforma. Propunha, ainda, que fosse criada uma nova estrutura de governança global para a nutrição com mecanismos mais eficientes de monitoramento do grau de cumprimento de compromissos e responsabilidades de cada um dos atores e que tivesse a participação da sociedade civil e do setor privado (LONGHURST, 2010).

A partir do biênio 2008/2009, inicia-se um processo de reforma do SCN. Entre outras, iniciou-se a discussão sobre as formas de se relacionar com o setor privado, especialmente com as indústrias de alimentos gerando um documento de diretrizes para a interação público-privada (UNSCN, 2015).

No momento atual, o SCN, agora denominado UNSCN, tem um mandato mais focalizado, dirigido à promoção da cooperação entre as agências da ONU e organizações parceiras em apoio ao nível comunitário, nacional, regional e global para o enfrentamento da fome e diversas formas da má nutrição. É gerido por um presidente e um Comitê Executivo. Suas

\footnotetext{
${ }^{11}$ http://www.thelancet.com/series/maternal-and-child-undernutrition.
} 
atividades são realizadas por meio de Grupos de Trabalho e Força Tarefas (UNSCN, 2015).

Além da estrutura do UNSCN, O Comitê de Segurança Alimentar (CSA) se mostra como uma outra iniciativa multilateral em âmbito global de facilitação e articulação entre diversos atores. O CSA é um organismo intergovernamental, criado em 1974, no âmbito das Nações Unidas, voltado a revisar e acompanhar as políticas de segurança alimentar (CSA, 2015).

A partir de 2009, foi iniciado um processo de reforma do Comitê Mundial de Segurança Alimentar $(C S A)^{12}$. A reestruturação do CSA teve como premissa dar "voz" a atores que estavam ausentes das discussões de segurança alimentar e nutricional no debate global, como as diferentes representações da sociedade civil organizada. Outro ponto que permeia a reforma do Comitê foi a incorporação da agenda de nutrição nas ações desenvolvidas no âmbito deste fórum global (CSA, 2015).

A estrutura atual do CSA é formada por: (1) um "bureau", que é o braço executivo do Comitê e funciona com uma presidência e 12 países membros ${ }^{13}$ em caráter rotatório; (2) um grupo consultor, formado por representantes das diferentes categorias de participantes do CSA, sendo elas, as agências da $\mathrm{ONU}^{14}$ incluindo o UNSCN, representantes da sociedade civil e organização não governamentais ${ }^{15}$, institutos de pesquisas, Banco Mundial, setor privado e instituições filantrópicas ${ }^{16}$. O papel deste grupo é apoiar o "bureau" a avançar nos objetivos do Comitê principalmente assegurando troca de informação com diferentes atores em nível regional, sub-regional e local; (3) a plenária, que se reúne anualmente, e define a agenda estratégica de ações e encaminhamentos; (4) o painel de especialistas de alto nível que prepara os

12 O Comitê Mundial de Segurança Alimentar (CSA) foi organizado em 1974 como um organismo intergovernamental para servir como um fórum para revisar e acompanhar as políticas de Segurança Alimentar. A visão é CSA reformado é ser uma plataforma intergovernamental mais inclusiva no nível internacional (http://www.fao.org/cfs/cfs-home/en/).

\footnotetext{
${ }^{13}$ Afeganistão, Argentina, Austrália, Brasil, Congo, França, Paquistão, Filipinas, Sudão, Suíça, Uganda e Estados Unidos.

${ }_{14}$ Food and Agriculture Organization (FAO), World Food Programme (WFP), International Fund for Agriculture Development (IFAD), Right to Food: Special Rapporteurs on the right to food, UM High Level Task Force on the Global Food Security Crisis; UN Standing Committee on Nutrition (SCN)

15 The World Forum of Fish Harvesters \& Fish Workers (WFHFF), Mouvement International de la Jeunesse Agricole (MIJARC), Indigenous Caucus (ICAZA) e World Alliance of Mobile Indigenous Peoples (WAMIP)

${ }^{16}$ Bill \& Melinda Gates Foundation e International Agri Food Network.
} 
conteúdos técnicos que dão base às discussões e decisões; e (5) o secretariado, que é responsável por apoiar o processo de trabalho das estruturas de governança do CSA (CSA, 2015).

Além destas estruturas multilaterais, observam-se em âmbito global outras iniciativas de articulação entre diversos atores e parceiros. Importante destacar que nem sempre as agendas e espaços de atuação destas são claramente organizados e distribuídos, de forma que cada nova instância agregue valor e/ou diferença ao todo. Em vários casos há sobreposição de agendas e dispersão de esforços.

Um exemplo, entre outros, é o Scaling Up Nutrition - SUN ${ }^{17}$. Esta iniciativa merece destaque uma vez que tem ganhado vulto e tem apoio de grandes doadores globais. O SUN foi lançado em 2010, a partir do protagonismo do Banco Mundial, da FBMG, de alguns países doadores e do setor privado para reforçar o enfrentamento da má-nutrição (SUN, 2015).

Esta iniciativa, segundo os documentos oficiais, surgiu pela necessidade de articulação em âmbito global de governos, sociedade civil, cidadãos e instituições privadas, para um esforço conjunto de eliminação da desnutrição e pela preocupação de que os países não alcançassem as metas dos Objetivos do Desenvolvimento do Milênio (SUN, 2015). O SUN, ao contrário das estruturas de governanças previamente citadas, não propõe a discussão e implementação de uma ampla agenda para o enfrentamento da má nutrição em todas as suas formas e que enfrente seus determinantes. Seu foco principal é a eliminação da desnutrição e, na prática, promove a implementação de ações nutricionais de caráter, sobretudo "curativo", baseadas em produtos alimentares para a recuperação nutricional de crianças desnutridas ou produtos fortificados com micronutrientes para o combate e controle de carências, embora no seu discurso proponha a ações de maior abrangência. Até o momento, aderiram ao SUN 55 países, sendo a maioria no continente africano, seguido pela Ásia e Américas Central e Sul (SUN, 2015).

\footnotetext{
${ }^{17}$ Scaling Up Nutrition é uma iniciativa de priorização de esforços para o enfrentamento da má-nutrição. Participam governos, sociedade civil, ONU, doadores, incluindo o setor privado. No conjunto de intervenções estão apoio ao aleitamento materno exclusivo até os 6 meses e continuidade da amamentação, juntamente com a introdução da alimentação complementar até 2 anos; fortificação de alimentos; suplementação de micronutrientes e tratamento de desnutrição (SUN, 2015).
} 
Ao longo da história, a multiplicação de iniciativas dirigidas, tanto à erradicação da fome como à articulação da agenda de nutrição, demonstram a dimensão de ambos os desafios e a importância dos interesses envolvidos. Tratar de governança global não significa favorecer exclusivamente as interações e engajamento de atores e instituições estritamente em âmbito global, mas sim, favorecer as estruturas de integração e coordenação também em outros níveis. Os espaços globais, regionais e sub-regionais podem fortalecer movimentos e posicionamentos de países. Assim, pode-se pensar em um fluxo político desta agenda em ambas as direções.

O próprio CSA coloca como desafio a integração e coordenação entre países, organizações e parceiros do nível nacional até global para a efetiva governança em segurança alimentar e nutricional (CSA, 2015).

Observa-se que os países organizam sua atuação em blocos, em diferentes níveis de agregação, inclusive blocos comerciais, com o intuito de utilizar o espaço político e estratégico para a integração, alinhamento e coordenação de agendas.

Um exemplo bem sucedido de como uma iniciativa global favorece movimento internos nos países foi a Convenção Quadro do Tabaco. Este foi um caso bem-sucedido de posicionamento conjunto com a construção e aprovação de uma agenda ambiciosa consolidada na forma de um tratado internacional cujas ações propostas, na maior parte regulatórias, tem caráter mandatório para os países que fazem a adesão. Acordos internacionais tem a capacidade de fortalecer os governos para atingirem metas de saúde pública (MAGNUSSON, 2000). O caso do tabaco demonstrou o quanto um tratado internacional mandatório é um mecanismo fundamental para apoiar os países a enfrentarem interesses econômicos em processos de regulação de mercados.

Outro exemplo, neste caso sub-regional, é o Mercosul. Este é um bloco econômico e união aduaneira, na qual há livre-comércio intrazona e política comercial comum entre seus membros. No entanto, também exerce papel político-estratégico e tem sido utilizado para a discussão e tomada de posição 
conjunta sobre diferentes temas que repercutem nas relações comerciais entre bloco, entre eles o tema de alimentos ${ }^{18}$.

No caso de nutrição, este bloco conta desde 2008 com uma "Estratégia Mercosul de Nutrição para a Saúde e Segurança Alimentar e Nutricional" (MERCOSUL, 2009)" a qual visa discutir, facilitar a cooperação internacional e coordenar posições políticas regionais relacionadas à nutrição. Propõe-se a facilitar a melhoria do padrão alimentar, do estado nutricional, da saúde e qualidade de vida das populações dos países membros (MERCOSUL, 2009).

Recentemente foi assinado pelos ministros da saúde que integram este bloco, um Acordo Mercosul de Recomendação de Políticas e Medidas Regulatórias para a Prevenção e Controle da Obesidade (MERCOSUL, 2015). Este acordo apresenta um conjunto de compromissos para o enfrentamento da obesidade com o enfoque regulatório, a exemplo de adoção de medidas regulatórias e fiscais, e busca aumentar o acesso e consumo de alimentos saudáveis e reduzir os não saudáveis; o aprimoramento da rotulagem nutricional; e a regulamentação de publicidade de alimentos não saudáveis.

Além destes exemplos citados, poderão haver outros espaços globais, regionais e sub-regionais estratégicos e articuladores que pretendam 0 fortalecimento de posicionamentos de países, grupos e distintos interesses no tema de nutrição.

O presente estudo se justifica diante deste cenário moldado com enorme carga de má nutrição e da premente necessidade de respostas rápidas, efetivas e focadas na determinação dos problemas nutricionais. A exploração das melhores formas de enfrentá-los e os parceiros necessários podem contribuir para o debate sobre a proposição de estratégias de reorientação da governança global de forma que sejam facilitados e garantidos espaços legítimos e efetivos de tomada de decisão democráticas e participativas, com respeito ao direito das populações à alimentação adequada e saudável e favorecendo a soberania alimentar dos países.

\footnotetext{
${ }^{18} \mathrm{Na}$ estrutura do MERCOSUL, há outras instâncias, além do GTSAN que discute temas de alimentos. $\mathrm{O}$ subgrupo de trabalho 3 é a instância de discussão de regulamentos técnicos. Nela são harmonizados os padrões de produtos, incluindo os produtos alimentícios, que são importados e exportados entre os países do bloco.
} 
Objetivo Geral: Identificar perspectivas e desafios da estruturação de processos para o enfrentamento da má nutrição do nível sub-regional ao global.

\section{Objetivos específicos:}

- Analisar a manifestação de países participantes da ICN2 em relação à agenda, atores e formas de atuação para o enfrentamento da má nutrição no nível global;

- Identificar desafios e potenciais de um bloco econômico, como o Mercosul, para influenciar a agenda de nutrição nos países membros;

- Explorar a percepção de pontos focais de nutrição no Mercosul quanto à compreensão e incorporação da obesidade nas suas agendas políticas, bem como o papel do Mercosul e da cooperação internacional para o combate a obesidade. 


\section{Método}

O presente estudo foi de natureza qualitativa. Segundo Minayo (2010), uma pesquisa com esta abordagem tem como característica identificar, explorar motivos, aspirações, valores e atitudes, ao lado de outros fenômenos que não podem ser quantificados, visando entender a complexidade de um determinado tópico, normalmente de natureza social, de interesse do pesquisador. A abordagem qualitativa é o que se aplica ao estudo da história, das relações, das representações, das percepções que os humanos fazem a respeito de como vivem, constroem, sentem, pensam (MINAYO, 2010).

A abordagem qualitativa foi, portanto, utilizada em função da expectativa do estudo de explorar manifestações e percepções de diferentes atores sobre o tema de interesse, neste estudo os países participantes da Segunda Conferência Internacional de Nutrição, e os pontos focais de nutrição para o Mercosul.

Os pronunciamentos dos países no ICN2 foram selecionados para análise uma vez que, representam na atualidade, o melhor conjunto de falas oficiais sobre nutrição no âmbito global e retratam os problemas nutricionais, preocupações e políticas e ações em marcha nos países, bem como seus desafios. Já, o olhar para o Mercosul permitiu identificar potenciais e desafios para que o mercado comum possa impulsionar a agenda de nutrição. Ainda, permitiu captar percepções dos pontos focais que compõem um grupo de segurança alimentar e nutricional no Mercosul, no sentido de como estes atores compreendem e incorporam em suas agendas políticas o enfrentamento da obesidade.

Todas as três etapas do estudo exploraram caminhos a serem trilhados para a governança global para nutrição, em função da articulação subregional.

A proposta metodológica escolhida articula algumas abordagens utilizadas em estudos qualitativos. MINAYO (2010) a denomina como triangulação metodológica. Esta pode ser compreendida como uma dinâmica de investigação que integra a análise das estruturas, dos processos e dos 
resultados, a compreensão das relações envolvidas na implementação das ações e a visão que os atores diferenciados constroem sobre todo um projeto fazendo dele um constructo (MINAYO, 2010).

Para isto, o estudo foi organizado em três momentos com o uso de técnicas diferenciadas e apropriadas para cada uma das situações e objetivos específicos, conforme detalhado a seguir.

\section{PRIMEIRO MOMENTO:}

Foi um estudo exploratório e descritivo, de base documental, composto por dados secundários provenientes dos pronunciamentos de 91 (71,6\%) dos 127 países participantes da ICN2 (FAO/OMS, novembro 2014). Esta etapa foi realizada de forma a explorar as manifestações e percepções dos países participantes da ICN2, no que diz respeito a agendas, atores em nível global.

Os pronunciamentos foram realizados por representantes de alto nível dos respectivos países, em sua maioria ministros de Estado. Assim, estes tinham legitimidade à época legitimidade para tal função que foi exercida neste evento de alto nível.

Segundo MINAYO, uma pesquisa de natureza qualitativa identifica e explora motivos, aspirações, valores e atitudes, ao lado de outros fenômenos que não podem ser quantificados, visando entender a complexidade de um determinado tópico, normalmente de natureza social, de interesse do pesquisador.

A análise dos pronunciamentos dos países foi feita a partir da análise de conteúdo. Esta autora a caracteriza como um conjunto de técnicas de análise das comunicações visando obter, por procedimentos sistemáticos, a descrição de conteúdos que permitam a inferência de conhecimento. Para a análise de conteúdo foi utilizada a técnica denominada, "Análise Lexical de Correspondência em Enunciados Simples de um Texto (Alceste ${ })$ ). Esta possibilita a exploração de percepções, experiências e pensamentos dos sujeitos da pesquisa, no caso os países. 
O Alceste é caracterizado pela associação entre métodos qualitativos e quantitativos de análise textual. A partir da análise empírica de ocorrências de palavras, é identificado no corpo de um texto os diferentes temas e ideias tratados que são então organizados em "classes de palavras". A técnica não é apropriada para testar hipóteses, e sim para explorar e descrever o conteúdo semântico mais frequente de textos.

As classes de palavras são hierarquizadas segundo Árvores de Classificação Descendente. Estas descrevem como as diferentes classes de palavras se relacionam e suas relações de força, por meio de uma figura no formato de "árvore com raízes". As raízes mais "profundas" representam a primeira divisão das palavras, e as mais superficiais, a última divisão das palavras.

Para a análise descritiva do vocabulário de cada classe de palavras foram utilizados dois critérios: (1) retenção de palavras com frequência maior que 6; e (2) retenção de palavras com o coeficiente phi maior que 0,2.

Considerando-se as características geopolíticas e linguísticas dos países participantes da Conferência, seus pronunciamentos, que neste estudo foram as unidades de contexto iniciais (UCls), foram organizados em seis corpus, a saber: África de língua inglesa, América do Norte (em inglês), América Latina (em espanhol), Ásia (em inglês), Europa (em inglês) e Oceania (em inglês). Para cada um dos seis corpus, que representou um arquivo de análise, optouse pela língua mais frequente do grupo de países. Assim, não foram incluídos nas análises os países que somente disponibilizaram discursos em outra língua oficial das Nações Unidas que não o inglês e o espanhol, a saber: português (Guiné Bissau); russo (Belarus, Armênia, Quijiquistao); árabe (Yemen, Iraque, Arábia Saudita, Líbano, Omã, Bahain); chinês (China); francês (Burundi, Afeganistão, Gabão, Costa do Marfim, Chade, Madagascar, Niger, Guiné, Mauritânia, Djibouti, Mali, República do Congo, Benim, Camarões, Tunísia, Burkina Faso, Marrocos, Suíça e França). A Espanha também foi excluída apesar de discursar em espanhol, pois esta diferiu da maioria do seu corpus (inglês). 
Em dois casos especiais, foi feita a tradução para a língua mais frequente dos respectivos corpus: o pronunciamento do Brasil foi traduzido para o espanhol para garantir sua integração na análise ao corpus da América Latina e o do México foi traduzido para o inglês para sua integração ao da América do Norte.

Uma alternativa para eliminar as diferenças linguísticas de forma a incluir a totalidade dos países na análise teria sido a tradução de todos os pronunciamentos para o inglês, língua mais frequente. No entanto, avaliou-se que tal tradução poderia fragilizar o estudo, pois poderia levar à perda de nuances linguísticas fundamentais no uso desta técnica.

\section{SEGUNDO MOMENTO:}

Caracterizou-se por uma análise documental sobre as estruturas e instâncias de trabalho no Mercosul que tratam de temas de alimentos e alimentação.

Foi realizado um levantamento considerando a estrutura organizacional do Mercosul, bem como seus processos de trabalho estabelecidos desde a sua criação em 1986.

Esta etapa foi relevante para o estabelecimento do roteiro de entrevistas semi-estruturada da etapa seguinte.

\section{TERCEIRO MOMENTO:}

Tratou-se de um estudo com abordagem qualitativa. Foram realizadas três entrevistas semiestruturadas ${ }^{10}$ em abril de 2012 com informantes chaves da Argentina, Brasil e Uruguai, que atuavam, na ocasião da entrevista, como pontos focais da Estratégia Mercosul de Nutrição para Saúde e Segurança Alimentar e Nutricional. O Paraguai estava momentaneamente fora do bloco no 
período das entrevistas inviabilizando a sua participação no momento das entrevistas.

O número de entrevistas foi reduzido. No entanto, representam o conjunto de países que no momento da pesquisa compunham o bloco subregional. Além disto, os informantes chaves dos países tinham legitimidade de resposta, uma vez que eram os pontos focais, representantes dos respectivos países neste Grupo de Trabalho o qual operacionaliza a Estratégia Mercosul de Nutrição para Saúde e Segurança Alimentar e Nutricional.

As entrevistas abrangeram os seguintes tópicos:

- Excesso de peso como um problema de saúde pública no país;

- Políticas e ações de enfrentamento, abordagens (setoriais ou intersetoriais), atores e papel da cooperação técnica internacional;

- Espaços do Mercosul para discutir obesidade e sua repercussão no planejamento e programação nacionais;

As entrevistas foram realizadas em espanhol, no caso da Argentina e Uruguai, e em português no caso do Brasil. Tiveram duração aproximada de 50 minutos e foram gravadas com o intuito de se registrar, da forma mais fidedigna possível, as percepções dos informantes-chave. Todas as entrevistas foram degravadas na língua original para a realização das análises.

A análise dos dados foi feita utilizando-se a Análise de Conteúdo ${ }^{11}$. Trata-se de um instrumento de pesquisa empregado para identificar palavraschave, frases e expressões dentro de um texto, ou conjunto de textos, de acordo com o objetivo do estudo. Ela possibilita a identificação de experiências, crenças, valores e pensamentos dos sujeitos e fontes de informação. Esta técnica consiste em buscar "núcleos de sentido".

Para a execução da técnica foram realizados:

(1) Pré-análise, que é a fase da organização do material analisado. É o momento da constituição do "corpus" de análise, ou seja, a degravação das entrevistas com os pontos focais; 
(2) Exploração do material, com uma leitura flutuante e destaque das ideias centrais e núcleos/categorias de sentidos das entrevistas;

(3) Tratamento dos resultados, com leituras e releituras do corpus;

(4) Interpretações em função das categorias identificadas;

Adicionalmente foi realizada uma revisão detalhada de documentos oficiais de domínio público dos três países, disponíveis no período entre novembro de 2014 e maio de 2015 nos websites oficiais dos respectivos Ministérios da Saúde dos países e, no caso do Brasil, no website do Ministério do Desenvolvimento Social e Combate à Fome, uma vez que as ações de enfrentamento da obesidade estão reunidas neste lócus.

O projeto foi submetido ao Comitê de Ética em Pesquisa da Faculdade de Ciências da Saúde da Universidade de Brasília. 
Resultados e Discussão 
Artigo 1 
O enfrentamento da má nutrição no nível global: uma análise dos pronunciamentos dos países na Segunda Conferência Internacional de Nutrição (ICN2)

Resumo: As populações do mundo padecem de múltiplas formas de má nutrição. A Segunda Conferência Internacional de Nutrição (ICN2) realizada em 2014 discutiu a relação entre as formas de má-nutrição e os sistemas alimentares. O presente estudo teve como objetivo analisar os pronunciamentos de 91 países participantes da ICN2 com vistas a identificar agendas, atores e formas de atuação para o enfrentamento da má-nutrição em âmbito global. Utilizou-se a técnica ALCESTE que identifica temas e ideias tratados em um corpo de texto e as formas de representá-los a partir da análise empírica de ocorrências de palavras. Os resultados indicam que os países descrevem seus problemas nutricionais de forma detalhada, sem retratar a sua determinação no mesmo nível de aprofundamento. São também mencionados a relação público-privada e a necessidade de proteção e fortalecimento do espaço político dos governos para o bom manejo de conflitos de interesse, introduzidos por relações inapropriadas com atores incluindo as corporações transnacionais. Pode-se concluir que as ações para o enfrentamento da má nutrição são insuficientes e o remodelamento dos sistemas alimentares não parece estar no centro das mudanças propostas. Há uma tendência maior dos países responderem aos problemas nutricionais vigentes de forma "curativa". Considerando que políticas neoliberais, incluindo a abertura de mercado e investimento estrangeiro, e o controle do sistema alimentar por poucas empresas transnacionais determinam esta situação, uma agenda de futuro deveria incluir medidas estruturantes que regulem o mercado de alimentos. Para tal, uma boa governança global para a nutrição é imprescindível e deve, entre outras medidas, contar com a participação da sociedade civil organizada dando voz a atores que se encontram à margem dos debates. É também primordial estabelecer-se critérios claros e transparentes para o relacionamento com o setor privado de forma a evitar conflitos de interesse.

Palavras chave: má nutrição, governança global, participação social, fortalecimento dos governos. 


\section{Abstract}

The world's populations suffer from multiple forms of malnutrition. The Second International Conference on Nutrition (ICN2) held in 2014 discussed the relationship between all forms of malnutrition and the food systems. This study aimed at analyzing the statements of 91 countries participating in the ICN2 in order to identify agendas, actors and approaches to address malnutrition globally. The ALCESTE technique was used to identify the themes and ideas presented in the text and their forms of representation by the empirical analysis of words' occurrences. The results indicate that countries describe their nutritional problems in detail, without an in depth portraying of their determinants. Public-private partnerships are mentioned as well as the need to protect and strengthen governments' policy spaces in order to manage potential conflicts of interest generated by the interaction with multi-actors including transnational corporations. It can be concluded that current actions to address malnutrition are still insufficient and the remodeling of the food systems does not seem to be at their core. There is a tendency for countries to respond to the current nutritional problems in rather a "curative" way. Given that neoliberal policies prevail, including market liberalization and foreign direct investments, and that the a few transnational companies control the food system, a future agenda should include structural measures to regulate the food system and the world's food markets. Global governance for nutrition is essential and should include social participation giving voice to actors who have been kept on the margins of the global debate, specially the peoples most affected by mal nutrition. It is also essential to establish clear and transparent criteria for the relationship with the private sector in order to avoid conflicts of interest.

Key words: malnutrition, global governance, social participation, government strength. 


\section{Introdução}

Nos dias atuais, as populações do mundo padecem de múltiplas formas de má nutrição. Estima-se que a desnutrição infantil na sua forma crônica afete 161 milhões de crianças menores de cinco anos no mundo. A subnutrição é ainda a mais importante causa de morte de crianças dessa faixa etária, tendo sido, em 2013, responsável por $45 \%$ da mortalidade neste grupo. Quanto às deficiências por micronutrientes estima-se que afetem atualmente mais de dois bilhões de pessoas ${ }^{1}$.

Ao mesmo tempo, na outra face da insegurança alimentar e nutricional estão o excesso de peso e a obesidade que têm aumentado em todas as regiões do mundo. Cerca de 42 milhões de crianças menores de 5 anos já eram afetadas pelo excesso de peso em 2013 e mais de 500 milhões de adultos eram obesos em $2010^{1}$.O sobrepeso e a obesidade não apenas são problemas de saúde em si, mas também fatores de risco para outras inúmeras doenças, representando uma grande carga social e sobrecarga para os serviços de saúde dos países.

Todos estes desfechos nutricionais desfavoráveis expressam violações ao direito humano à alimentação adequada e saudável e têm, entre suas causas, a configuração dos sistemas alimentares dos países, isto é, a forma como produzem, processam, comercializam e consomem alimentos. Consequentemente, estes desfechos são, em última análise, também responsabilidade dos atores que controlam esses sistemas alimentares ${ }^{2,3,4}$.

O sistema alimentar nunca esteve tão concentrado e controlado por tão poucos: os treze maiores conglomerados industriais de alimentos do mundo (Nestlé, Monsanto, Bungue, Dreyfuss, Kraft Foods, Pepsi-cola, Coca Cola, Unilever, Tyson Foods, Cargill, Marte, ADM, Danone) detém 26\% do mercado global e 100 cadeias de venda direta ao consumidor controlam $40 \%$ do comércio varejista de alimentos ${ }^{5}$. Muitas vezes são as empresas transnacionais e não os governos dos países que definem e implementam as macropolíticas estratégicas de abastecimento alimentar ${ }^{2}$. 
Diante deste cenário, é urgente uma resposta global mais rápida e assertiva que se dirija não apenas para o tratamento da má nutrição, mas, sobretudo, para o equacionamento de seus determinantes com vistas à proteção do direito humano à alimentação adequada e garantia da soberania alimentar dos países.

Entende-se fundamental ter-se uma governança global efetiva da nutrição, ou seja, um arcabouço de interação e engajamento de atores e instituições no âmbito global coordenados com os níveis regionais e nacionais que abarque e possa influenciar múltiplos setores como agricultura, saúde, meio ambiente, comércio, desenvolvimento, proteção social e direitos humanos.

É imperioso também favorecer a participação legítima de grupos e populações afetadas pela insegurança alimentar e desnutrição, representados pela sociedade civil organizada e movimentos sociais, privilegiando que na estrutura do processo de decisório não sejam perpetuadas as desiguais relações de poder existentes. E, por fim, estruturas de governança nas quais os governos sejam protagonistas dos processos de decisão e que o espaço político seja protegido de conflitos de interesse ${ }^{6,7,8,9,10}$.

Entre 1999 e 2008, o Comitê Permanente de Nutrição da ONU (SCN) desempenhou o papel de harmonização das iniciativas de agências intergovernamentais e também de articulação com a sociedade civil (Valente, 2015), preenchendo, mesmo de que forma incompleta, um papel na governança global para a nutrição. Este Comitê propôs a primeira edição da Conferência Internacional de Nutrição (ICN), ocorrida em 1992, com representantes de mais de 159 países. A Conferência publicou uma declaração política e um plano de ação que motivaram a elaboração de Planos Nacionais para a Ação em Nutrição, nos quais os países definiram suas prioridades e que serviram como mecanismos para a mobilização política e orçamentária para os programas nacionais ${ }^{11,12}$.

Mais de duas décadas após a primeira ICN, a Segunda Conferência Internacional de Nutrição (ICN2) foi promovida pela Organização das Nações Unidas para a Alimentação e Agricultura (FAO) e Organização Mundial da 
Saúde (OMS) em Roma. As discussões, em 2014, centraram-se na relação entre a má nutrição e os sistemas alimentares. O evento teve a participação de delegados de mais de 170 países, 150 participantes da sociedade civil, representantes do setor privado, parlamentares e agências das Nações Unidas ${ }^{1}$. Discutiram-se os múltiplos desafios da má nutrição para o desenvolvimento inclusivo, sustentável e promotor de saúde sob o ponto de vista de diferentes atores, inclusive contando com representantes dos dois paradigmas antagônicos mencionados.

Como de praxe, os países tiveram a oportunidade de emitirem suas posições na forma de pronunciamentos. Foram realizados encontros da sociedade civil, iniciativa privada e parlamentares que antecederam a Conferência ${ }^{1}$. Seus posicionamentos, à exceção do setor privado, foram evidenciados nos documentos divulgados ao final da Conferência ${ }^{8,13}$.

A Conferência adotou uma declaração política ${ }^{14}$ e uma matriz que apresenta sugestões de ações e políticas a serem implementadas pelos países ${ }^{15}$.

Considerando a importância do posicionamento proativo dos países para o enfrentamento não apenas dos problemas relacionados à má nutrição, mas, principalmente dos seus determinantes, este estudo teve como objetivo a análise exploratória dos pronunciamentos de 91 países participantes da II Conferência Internacional de Nutrição com vistas a identificar como se manifestam em relação à agenda, atores e formas de atuação no enfrentamento da má nutrição.

\section{Método}

Trata-se de um estudo qualitativo, exploratório e descritivo, de base documental composta por dados secundários provenientes dos pronunciamentos de $91(71,6 \%)$ dos 127 países participantes (FAO/OMS, novembro 2014) que fizeram pronunciamentos na ICN2. Os pronunciamentos são de domínio público e estão disponíveis no website http://www.fao.org/about/meetings/icn2/en/. 
Os pronunciamentos foram realizados por representantes de alto nível dos respectivos países, em sua maioria ministros de Estado. Assim, estes tinham legitimidade à época legitimidade para tal função que foi exercida neste evento de alto nível.

Segundo Minayo $^{16}$, uma pesquisa de natureza qualitativa identifica e explora motivos, aspirações, valores e atitudes, ao lado de outros fenômenos que não podem ser quantificados, visando entender a complexidade de um determinado tópico, normalmente de natureza social, de interesse do pesquisador.

A análise dos pronunciamentos dos países foi feita a partir da análise de conteúdo ${ }^{17}$ Esta autora a caracteriza como um conjunto de técnicas de análise das comunicações visando obter, por procedimentos sistemáticos, a descrição de conteúdos que permitam a inferência de conhecimento. Para a análise de conteúdo foi utilizada a técnica denominada, "Análise Lexical de Correspondência em Enunciados Simples de um Texto (Alceste $®$ )". Esta possibilita a exploração de percepções, experiências e pensamentos dos sujeitos da pesquisa, no caso os países.

O Alceste é caracterizado pela associação entre métodos qualitativos e quantitativos de análise textual ${ }^{18}$. A partir da análise empírica de ocorrências de palavras, é identificado no corpo de um texto os diferentes temas e ideias tratados que são então organizados em "classes de palavras ${ }^{19}$. A técnica não é apropriada para testar hipóteses, e sim para explorar e descrever o conteúdo semântico mais frequente de textos.

As classes de palavras são hierarquizadas segundo Árvores de Classificação Descendente. Estas descrevem como as diferentes classes de palavras se relacionam e suas relações de força, por meio de uma figura no formato de "árvore com raízes". As raízes mais "profundas" representam a primeira divisão das palavras, e as mais superficiais, a última divisão das palavras. 
Para a análise descritiva do vocabulário de cada classe de palavras foram utilizados dois critérios: (1) retenção de palavras com frequência maior que 6; e (2) retenção de palavras com o coeficiente phi maior que $0,2^{20}$.

Considerando-se as características geopolíticas e linguísticas dos países participantes da Conferência, seus pronunciamentos, que neste estudo foram as unidades de contexto iniciais (UCls), foram organizados em seis corpus, a saber: África de língua inglesa, América do Norte (em inglês), América Latina (em espanhol), Ásia (em inglês), Europa (em inglês) e Oceania (em inglês). Para cada um dos seis corpus, que representou um arquivo de análise, optouse pela língua mais frequente do grupo de países. Assim, não foram incluídos nas análises os países que somente disponibilizaram discursos em outra língua oficial das Nações Unidas que não o inglês e o espanhol, a saber: português (Guiné Bissau); russo (Belarus, Armênia, Quijiquistao); árabe (Yemen, Iraque, Arábia Saudita, Líbano, Omã, Bahain); chinês (China); francês (Burundi, Afeganistão, Gabão, Costa do Marfim, Chade, Madagascar, Niger, Guiné, Mauritânia, Djibouti, Mali, República do Congo, Benim, Camarões, Tunísia, Burkina Faso, Marrocos, Suíça e França). A Espanha também foi excluída apesar de discursar em espanhol, pois esta diferiu da maioria do seu corpus (inglês).

Em dois casos especiais, foi feita a tradução para a língua mais frequente dos respectivos corpus: o pronunciamento do Brasil foi traduzido para o espanhol para garantir sua integração na análise ao corpus da América Latina e o do México foi traduzido para o inglês para sua integração ao da América do Norte.

Uma alternativa para eliminar as diferenças linguísticas de forma a incluir a totalidade dos países na análise teria sido a tradução de todos os pronunciamentos para o inglês, língua mais frequente. No entanto, avaliou-se que tal tradução poderia fragilizar o estudo, pois poderia levar à perda de nuances linguísticas fundamentais no uso desta técnica.

A tabela 1 apresenta um resumo de informações básicas sobre os seis corpus. As "Unidades de Contexto Inicial (UCls)" são os pronunciamentos dos países. Com exceção da América do Norte e Oceania, há número suficiente de 
palavras em cada corpus para um uso adequado da técnica, uma vez que se recomenda um mínimo de 10.000 palavras para cada análise.

\section{Resultados}

Os 91 pronunciamentos foram organizados em seis corpus de análise (tabela 1). O conteúdo central das análises está apresentado destacando as diferentes perspectivas e os aspectos comuns às formas narrativas dos países de cada corpus em relação às questões de alimentação e nutrição. Na tabela 2 estão apresentadas as seis árvores de classificação descendente.

\section{Descrição de cada corpus:}

\section{1. África:}

A primeira classe de palavras descreve os problemas nutricionais, com maior foco na deficiência de micronutrientes (anemia, deficiência de vitamina $A$, entre outros), além da fome e da desnutrição. Há também a preocupação com a dupla carga de má nutrição, caracterizada pela coexistência da desnutrição e taxas crescentes de excesso de sobrepeso/obesidade e doenças crônicas não transmissíveis (DCNT).

$\mathrm{Na}$ segunda classe de palavras, apresentam-se respostas à situação nutricional apontada na classe 1. Destaca-se um conjunto de ações dos setores da agricultura, pesca, saúde, comércio de alimentos, consumo e proteção social. Observa-se fortemente a valorização da coerência e coordenação: "realização de ações e políticas coerentes e coordenadas para aprimorar a segurança alimentar e nutricional” complementada pela “... a necessidade de mobilização de recursos necessários para o aprimoramento...". Este discurso está articulado à lógica de que as intervenções nutricionais requerem "boa governança e forte colaboração com parceiros como as agências da ONU, sociedade civil e o setor privado". O "movimento Scalling Up Nutrition (SUN)" é citado como plataforma de coordenação e governança das ações. Ressalta-se que este movimento baseia-se principalmente na 
implementação de ações nutricionais que empregam produtos alimentares fortificados com micronutrientes para a recuperação nutricional.

A terceira classe apresenta o endosso a declarações e documentos políticos em nível global como a "Rome Declaration" e "Framework for Action", ambas declarações finais do ICN2. A quarta classe apenas inclui agradecimentos e cumprimentos aos organizadores do evento.

\subsection{América do Norte:}

Neste corpus foram geradas 7 classes de palavras, sendo que 5 relacionadas aos pronunciamentos dos Estados Unidos e Canadá (classes $1,2,3,6$ e 7 ), somando $72 \%$ das palavras. E, outras 2 classes de palavras (classes 4 e 5), com características relacionadas ao pronunciamento mexicano, somando $28 \%$ das palavras identificadas.

Este corpus, pelo número reduzido de países (3) e por um número reduzido de palavras (1.722) tem limitações e difere dos outros. Além do mais, este foi um corpus com conteúdo não homogêneo em função das grandes diferenças entre os países. A heterogeneidade do corpus explica o fato da primeira divisão de palavras ter separado os pronunciamentos do México em relação aos do Canadá e Estados Unidos.

No caso das duas classes referentes ao México, observa-se uma tendência de posicionamento e comprometimento político deste país com a luta contra a fome e a pobreza para o alcance da segurança alimentar e nutricional, tanto na perspectiva nacional como global.

No segundo grupo, dos Estados Unidos e Canadá, destacam-se elementos relativos à descrição da situação epidemiológica/nutricional (obesidade e doenças crônicas não transmissíveis) e ações no âmbito das políticas públicas, com destaque para a redução da morbi-mortalidade infantil, a iniciativa "1,000 dias e também estratégias voltadas a eliminar a deficiência de vitaminas e minerais (...micronutrientes para a melhora das funções cognitivas e desenvolvimento de cérebros saudáveis...). 
A estratégia de 1,000 dias é uma iniciativa lançada nos Estados Unidos voltada para fortalecer às ações na nutrição materno infantil. É apoiada pela Fundação Bill e Melinda Gates e SUN.

Além disto, Canadá e Estados Unidos utilizam-se do discurso de "construir um sistema alimentar saudável" provendo "nutrientes adequados", com apoio do setor privado, de organizações não governamentais em um sistema global de mercado transparente. O SUN é citado também como plataforma de coordenação de setores e parceiros, assim como aparece nos países africanos.

As classes 6 e 7 ressaltam a importância do estabelecimento das parcerias públicos-privadas, incluindo questões de garantia de orçamentos para o enfrentamento da fome no mundo e a inserção da agenda global da nutrição na "agenda pós 2015". "...acreditamos que esta Conferência deve prover fortemente as discussões da agenda pós-2015. A classe 7 retrata, especificamente, a importância do setor privado para o alcance das metas pós2015.

\subsection{América Latina:}

Os discursos dos países da América Latina geraram 5 classes de palavras. A primeira compreende ações que já vem sendo realizadas em relação a boas práticas e manejo de alimentos do ponto de vista sanitário.

$\mathrm{Na}$ segunda destacam-se os posicionamentos de ratificação de compromissos internacionais para a erradicação da fome e da garantia da nutrição adequada, respaldadas em marcos legais e na perspectiva do direito humano de todos os povos do mundo. São ainda marcas importantes na segunda classe de palavras: a necessidade de se colocar o tema da nutrição na agenda política dos parlamentos e frentes parlamentares dos países; a importância de alianças políticas nos níveis sub-regionais, regionais e global para o enfrentamento conjunto ao poder econômico e político das indústrias de alimentos; e o compromisso com a cooperação entre países, sejam bilateral, sul-sul ou triangular. 
A terceira classe de palavras, que agrupou o maior percentual de palavras (45\%), descreve ações realizadas, mas de conteúdo bastante diferente da classe 1. Há, por exemplo, menção de marcos legais para segurança alimentar e nutricional e de promoção de ciclos virtuosos de desenvolvimento, com recuperação de valores sociais, restituição de direitos e fortalecimento de capacidades.

As classes 4 e 5 descrevem os problemas nutricionais. Sendo que a quarta classe esta relacionada às práticas alimentares com ênfase na necessidade de diminuição do conteúdo de energia dos alimentos processados provenientes de açúcares e gorduras e a importância do resgate das tradições e culturas alimentares. E, a classe 5, trata dos problemas nutricionais descrevendo as prevalências de desnutrição, excesso de peso e outros.

\section{4. Ásia:}

A análise do corpus dos países asiáticos gerou 6 classes de palavras. A primeira destaca o impacto potencial de mudanças climáticas nos problemas nutricionais, por afetarem tanto a produção agrícola como o acesso e a disponibilidade de alimentos. Esta classe expõe ainda o reconhecimento e valorização da cultura alimentar e culinária japonesa, como elemento positivo para a promoção de hábitos alimentares saudáveis.

A segunda classe de palavras enfatiza o posicionamento dos países em relação à agenda global de nutrição e aos documentos resultantes da Conferência, dando destaque ao bloco econômico da Ásia, denominado Associação de Nações do Sudeste Asiático (ASEAN) como espaço políticoestratégico para a integração e alinhamento de agendas e ações.

As classes 3 e 4 apresentam os esforços para o enfrentamento da carga de doenças com um forte enfoque para a desnutrição e carência de micronutrientes, apesar de também aparecer o controle da obesidade.

A quinta classe de palavras enfatiza a importância de mobilizar os setores públicos e privados para o alcance de metas nacionais e globais. Além 
de reconhecer a importância do apoio da comunidade internacional aos países para o alcance de resultados. Destaca-se nesta classe, ainda, a menção à necessidade de legislação para banir a venda de alimentos não saudáveis nas escolas.

Por último, na classe 6 encontra-se apresentada a importância do desenvolvimento de planos nacionais de nutrição e de políticas públicas multisetoriais para assegurar a segurança alimentar e nutricional das populações. Observam-se nos pronunciamentos alerta para a necessidade de liderança para agendas relacionadas à agricultura e nutrição.

\subsection{Europa:}

A análise do corpus da Europa gerou 4 classes de palavras sendo que a classe 1 representa a maioria absoluta (68\%) das palavras identificadas como mais relevantes. Nesta classe destaca-se a descrição de ações de nutrição na perspectiva da prevenção e promoção da saúde. Estas ações não são somente da área da saúde, mas incluem um conjunto de políticas públicas no escopo do sistema alimentar como o estímulo à produção local e à agricultura familiar, a facilitação do acesso a alimentos saudáveis (orgânicos, por exemplo), a realização de feiras e mercados locais, entre outras.

Ainda no que diz respeito a facilitar o acesso a alimentos saudáveis, os pronunciamentos destacam a focalização no público infantil pela oferta de alimentos produzidos localmente em equipamentos públicos como creches e escolas e pela realização de campanhas educativas e também tem um enfoque do desenvolvimento da economia local. A regulação da publicidade de alimentos para crianças foi um tema mencionado.

Na segunda classe de palavras deste corpus, $10 \%$ do total, é ressaltada a necessidade de que as agendas foquem na múltipla carga da má nutrição, pois, apesar da atual carga de doenças estar mais presente na obesidade e doenças crônicas e não transmissíveis, ainda é necessário olhar para as mazelas da fome e pobreza no mundo. 
Na classe 3, destacam-se trechos sobre a importância da manutenção da agenda de nutrição em alto nível no âmbito global e do papel das agências das Organizações das Nações Unidas e outros órgãos, parceiros e doadores para este fim. O movimento "Scalling Up Nutrition" é referenciado como mobilizador de recursos e energias.

Há também referências sobre o endosso a metas globais de nutrição acordadas, na Assembleia Mundial da Saúde, bem como o endosso aos documentos políticos da Conferência.

Finalmente, na classe 4, observam-se apenas os agradecimentos de praxe pela organização do evento.

\subsection{Oceania:}

A análise do corpus da Oceania gerou 6 classes de palavras. $\mathrm{Na}$ primeira classe está presente a importância do conceito de "soberania alimentar" para os países daquela região e a problemática do aumento da importação de produtos industrializados em detrimento dos alimentos tradicionais produzidos localmente. Há preocupações relacionadas à forte dependência na aquisição e consumo dos produtos importados e, por consequência, mudanças de preferências e práticas alimentares nestes países.

Na classe 2 encontra-se a descrição de ações desenvolvidas com foco no fortalecimento de ações regulatórias e no direito à escolha de alimentos saudáveis pelo cidadão. Os discursos desta região tratam desde o aperfeiçoamento de normas internacionais desenvolvidas pelo Codex Alimentarius, ao apoio ao consumidor para escolhas informadas mais saudáveis. Normas sanitárias como rotulagem nutricional e fortificação mandatória e voluntária foram alguns exemplos.

As classes 3 e 4 reúnem o perfil epidemiológico e nutricional dos países, com ênfase na obesidade e nas DCNT e na sua relação com o aumento do consumo de produtos importados. Na classe 4 identificam-se, ainda, alguns elementos sobre como os países vem enfrentando tal situação. 
Por fim, as classes 5 e 6 reúnem os posicionamentos dos países no nível internacional. Observam-se trechos que ratificam documentos e compromissos (i.e. a agenda de desenvolvimento pós-2015), e o posicionamento político destes países em favor da segurança alimentar e nutricional: "Enquanto co-chair da FAO... Austrália está trabalhando com a FAO para melhor apoiar os países da região no que diz respeito aos desafios relacionados à segurança alimentar e nutricional..." e "A Austrália é um membro ativo da OMS para a agenda de desenvolvimento pós-2015".

\section{Discussão}

A análise dos pronunciamentos permitiu identificar caminhos que os países estão trilhando para o enfrentamento da má nutrição e como externalizam suas visões, preocupações e perspectivas futuras.

\section{Caracterização dos problemas nutricionais e seus determinantes}

Observa-se que apesar dos países reconhecerem e descreverem seus problemas nutricionais, caracterizando-os em função das diversas formas de má nutrição, foi possível identificar a pouca dedicação à análise dos determinantes desses problemas. Embora o termo "sistema alimentar" tenha sido bastante utilizado nos pronunciamentos, de maneira geral este é citado com pouca referência ao fato de que a estrutura atual desse sistema, pautada por interesses econômicos e que transformou os alimentos em mercadorias ${ }^{2,3}$, é determinante central da má nutrição. Apenas na Ásia, Europa e Oceania a reflexão sobre o papel dos sistemas alimentares é mencionada, mas com abordagens distintas.

$\mathrm{Na}$ Ásia, os problemas nutricionais foram associados às mudanças climáticas que afetam a produção e dificultam o acesso aos alimentos. De fato, o sistema alimentar hegemônico baseado na produção intensiva degrada mais rapidamente os solos, contribuindo ainda mais para as mudanças climáticas. Não ficou evidente nos pronunciamentos dos países, por exemplo, a 
necessidade de se fortalecer sistemas mais sustentáveis e diversificados, como aqueles baseados na agroecologia. Além de importantes para a estabilidade do clima do planeta, os sistemas agroecológicos podem fornecer alimentação mais variada melhorando a oferta de nutrientes para as populações ${ }^{21,22,23}$.

No caso da Europa, de uma forma geral, as abordagens de prevenção e promoção da saúde associam-se a um conjunto de políticas públicas que visam a tornar o sistema alimentar mais responsivo à nutrição. Observa-se, neste grupo de países, a importância dada à agricultura de pequena escala a exemplo da agricultura familiar, que pode ser mais sustentável e diversificada. Assim, políticas de investimento no setor agrícola e nos pequenos agricultores familiares para a proteção dos sistemas alimentares locais e garantia de condições mais justas e equitativas, são demandadas por diversas organizações e também pelo Relator Especial de direito humano à alimentação da ONU ${ }^{21,23}$. A sociedade civil defendeu esta posição no ICN2 ${ }^{8}$.

Já na Oceania, observou-se a tendência a uma visão mais crítica das relações de mercado, com a valorização dos sistemas alimentares locais e do paradigma da Soberania Alimentar. Os países mencionaram os riscos da entrada indiscriminada de alimentos importados, quase sempre processados e ultraprocessados, dada a sua relação com as crescentes prevalências de obesidade e doenças associadas.

Nas últimas duas décadas, em todo o mundo, os sistemas alimentares nacionais tradicionais vêm sendo paulatinamente modificados pelos grandes investimentos transnacionais, pelo livre-comércio de alimentos e pelo uso intensivo de práticas de marketing e publicidade de alimentos ${ }^{3,4}$, 24. Estima-se que o crescimento recente dos lucros e do valor de mercado dessas corporações venha da venda de alimentos processados e ultra processados preponderamente nos ditos "novos mercados" (países de baixa e média renda) 4, 25 . Em nível mundial, as vendas dos alimentos ultra processados aumentaram em $43,7 \%$. Os países em desenvolvimento são mercados mais atrativos para a penetração das indústrias transnacionais ${ }^{4}$.

A dependência de produtos importados é uma das principais causas do aumento da obesidade no mundo em desenvolvimento ${ }^{21,24}$. A cada aumento 
de 20 unidades (em quilogramas) em vendas anuais per capita de alimentos processados está associado um aumento de 0,28 pontos de Índice de Massa Corporal ${ }^{4}$.

Políticas neoliberais, como o estabelecimento de acordos de livremercado e abertura dos países ao investimento estrangeiro, favorecem a disseminação global das "commodities não saudáveis", isto é de tabaco, álcool e alimentos ultra processados, pelas corporações transnacionais. Estas políticas são prejudiciais à produção local de alimentos e geram a dependência alimentar dos países. Uma situação que nem atende às necessidades nutricionais e nem promove a saúde das populações do mundo. Ao contrário, contribui fortemente para a determinação de doenças além de não permitir que os países alcancem sua soberania alimentar ${ }^{3,4,26}$. No entanto, nos pronunciamentos dos países no ICN2 este entendimento não transparece de forma importante.

\section{Ações em andamento e o que deveria estar sendo feito segundo os países}

De maneira geral, segundo os seus pronunciamentos oficiais, há uma tendência maior dos países responderem aos problemas nutricionais vigentes de forma mais direta e "curativa", principalmente com o uso de suplementação e fortificação dos alimentos com micronutrientes. Encontram-se também iniciativas para um melhor sistema alimentar. Mas, sem o investimento necessário no remodelamento estrutural dos sistemas alimentares.

Nos países da África, América do Norte e Ásia observa-se a abordagem técnica dos problemas nutricionais com a menção de medidas de suplementação e fortificação de alimentos com micronutrientes. Esta tendência coincide com as regiões nas quais o SUN está mais presente, inclusive como uma plataforma de governança com multi atores e com a participação do setor privado.

Até o momento aderiram ao SUN 55 países distribuídos nas Américas, África e Ásia ${ }^{11}$, sendo que somente 4 estão nas Américas. Esta iniciativa 
estrutura-se em cinco redes que reúnem governos, sociedade civil, Nações Unidas, doadores e o setor privado. O SUN estabeleceu parceria com 158 empresas. São 44 multinacionais com o foco em biofortificação/fortificação, suplementos de micronutrientes, cadeia de abastecimento e logística, propaganda e marketing, educação nutricional, pesquisa, sistema de informação, comunicação e tecnologia. Entre estas empresas, encontram-se algumas das maiores corporações agro-alimentares do mundo como Cargill, Pepsico e Unilever ${ }^{11}$.

$\mathrm{Na}$ América Latina as ações nutricionais foram apresentadas no contexto de planos e leis de Segurança Alimentar e Nutricional. E, diferentemente de outras regiões, mencionou-se o enfoque nas populações mais vulneráveis e restituição de direitos humanos. Na Ásia foi dada a importância do desenvolvimento de planos nacionais de nutrição e de políticas públicas multisetoriais para assegurar a segurança alimentar e nutricional das populações.

Com exceção da América do Norte, observa-se a tendência de preconizar a regulação da propaganda de alimentos e da venda de alimentos não saudáveis em cantinas escolares. Este tema aparece mais frequentemente nos pronunciamentos que tratam a necessidade $\mathrm{e}$ as dificuldades de enfrentamento com as grandes corporações. Apesar das evidências entre publicidade de alimentos e consumo serem claras ${ }^{24,25,27}$ é conhecido que medidas desta natureza são muito difíceis de serem incorporadas nas agendas políticas dos países em função dos interesses da indústria de alimentos e de comunicação ${ }^{4,24,25}$.

Na América Latina, o tema da regulamentação é tratado com ênfase na necessidade de se agregar forças de diversos setores sociais, incluindo a sociedade civil e a comunidade internacional. A articulação com a rede de parlamentares em âmbito global foi apontada pelos países, como uma estratégia relevante para levar a nutrição para o alto nível político e enfrentar os grandes desafios de regulamentação. A declaração final "para uma boa nutrição" oriunda do encontro prévio de parlamentares na ICN2 aponta a necessidade de desenvolver legislação para o aprimoramento da rotulagem 
nutricional, para a promoção e proteção do aleitamento materno, para o controle da publicidade de alimentos, entre outras ${ }^{13}$. A Estratégia sub-regional "América Latina sem Fome", fomentada pela $\mathrm{FAO}$, foi o processo indutor da articulação da rede de parlamentares ${ }^{28}$.

Ainda no que diz respeito às normas regulatórias visando à proteção da saúde das populações, somente a Oceania destacou a necessidade de aperfeiçoamento de padrões internacionais preconizados pelo Codex Alimentarius para facilitar a escolha informada do consumidor. Este é um organismo que

Mas, nem na Oceania e nem nas outras regiões, houve problematização sobre a influência que estruturas como Códex, Organização Mundial do Comércio (OMC) e blocos regionais comerciais exercem nas relações de mercados entre os países ${ }^{29,30,31}$. A eliminação de cotas e redução de tarifas, a partir da década de 80 , foi responsável pela facilitação da entrada de alimentos ultra processados nos países que mantém relações comerciais bilaterais, multilaterais e também por meio dos mercados regionais ${ }^{29,30,32}$.

O Acordo Geral de Tarifas e Comércio - GATT, firmado no âmbito da OMC, é um mecanismo global de negociação de relações comerciais. Há um artigo neste acordo que diz respeito à proteção da saúde das populações na perspectiva do alimento seguro ${ }^{29}$. Valendo-se deste artigo, embora sua visão da segurança alimentar e nutricional seja bastante restrita, poder-se-iam aventar possibilidade de discussão de medidas de proteção da alimentação saudável.

Por último, em algumas regiões foi destacado o papel estratégico de blocos comerciais com o Asean e o Mercosul para o estabelecimento de medidas consideradas mais difíceis de serem implementadas, como a regulação de publicidade de alimentos. 


\section{As parcerias público-privadas e a participação da sociedade civil organizada}

No corpus da América do Norte e Ásia as parcerias público-privadas foram destacadas como importantes para o alcance de objetivos e metas globais no âmbito dos Objetivos do Desenvolvimento Sustentável.

No entanto, não foi observada a menção de critérios para o manejo destas relações de forma a evitar conflitos de interesse. Tão pouco foi dado destaque para a importância da participação da sociedade civil organizada, notadamente das populações mais afetadas pela má nutrição, em processos e estruturas de governança global para a nutrição.

O movimento SUN foi citado no contexto da necessidade de políticas coerentes e coordenadas para uma boa governança da nutrição. O setor privado está incluído. A participação de grandes indústrias de alimentos no

SUN é alvo de críticas de vários setores da sociedade civil. Alega-se a existência de conflito de interesses, uma vez que o SUN promove ações que criam oportunidades comerciais para essas empresas que passam a participar na concepção de políticas de segurança alimentar e nutricional, colocando em risco a soberania alimentar dos países integrantes. Um exemplo são as empresas de tecnologia e insumos para a fortificação e suplementação de alimentos. A promoção deste tipo de estratégia de combate à má nutrição por micronutrientes preconizada pelo SUN deve ser transparente e isonômica, fazendo uso de produtos diversos disponíveis no mercado local e não dando ênfase aos produtos de algumas parceiras ${ }^{7}$.

Para a discussão das parcerias público-privadas e potenciais conflitos de interesses é importante ter clareza sobre as estratégias utilizadas pelo setor privado para influenciar o setor público. Faz-se necessária a definição da relação institucional e política a ser estabelecida entre o Estado e o setor privado cujas práticas podem entrar em conflito com os princípios das políticas públicas. Muitas vezes o setor privado apresenta-se nesses fóruns como sociedade civil, por meio de ONGs e, ainda, usando no seu discurso conceitos de Direito Humano e Soberania Alimentar ${ }^{33}$. Segundo Moodie et al ${ }^{25}$, as Nações Unidas e alguns governos são a favor do estabelecimento destas 
parceiras público-privadas na área de nutrição desde que sejam definidos previamente os resultados esperados e que também sejam monitoradas para uma avaliação da sua efetividade.

No cenário global da nutrição, que conta com a participação de atores com interesses diversos e uma gama de indústrias bastante diversificadas que atuam em toda a cadeia alimentar (desde insumos agrícolas, passando por fórmulas alimentares fortificadas até a comercialização de alimentos de todas as naturezas), faz-se necessário o estabelecimento de critérios claros, bem como a construção de estruturas de governança em que estejam incluídos representantes dos mais vulneráveis ${ }^{34}$. A participação efetiva da sociedade civil na governança global para a nutrição legítima a cobrança para que os governos se posicionem pela proteção da saúde, da segurança alimentar e nutricional das populações e pela soberania alimentar dos países.

O Comitê Mundial de Segurança Alimentar e Nutricional (CSA) vem sendo considerado um elemento chave para a renovação da governança global para a nutrição, uma vez que tem contado com a participação de atores da sociedade civil organizada de diferentes regiões do mundo e que antes estavam à margem dos debates internacionais ${ }^{34,35,36}$. O Marco Estratégico Global do CSA é considerado uma conquista, embora ainda faz-se necessária a articulação mais robusta entre as discussões nacionais e regionais, como em âmbito internacional, especialmente para fazer a voz da sociedade civil ser mais ouvida em todas as esferas ${ }^{37}$.

O espaço político dos governos precisa ser protegido de conflito de interesse. Governos e instituições internacionais precisam proteger os interesses públicos ${ }^{38}$. O Estado com participação social é capaz de prover regulação das políticas públicas para o alcance da segurança alimentar e nutricional. A ação regulatória alinhada aos interesses públicos é fundamental para a defesa dos direitos e alcance da soberania alimentar dos países ${ }^{25,33}$. 


\section{Conclusões}

Diante dos achados, conclui-se que as agendas e prioridades atuais estão transitando entre o enfrentamento das carências/déficits e dos excessos nutricionais. De uma forma geral, embora haja reconhecimento parcial dos determinantes da má nutrição relacionados à configuração atual dos sistemas alimentares, estes não estão sendo enfrentados.

Apesar do enfrentamento à obesidade e às DCNTs fazer parte das agendas dos países, as ações que estão colocadas em marcha são tradicionais e insuficientes. O "remodelamento dos sistemas alimentares" não está na ordem do dia. No que diz respeito aos atores e formas de atuação estas estão no momento atual, focados em ações "curativas" e potencializando o interesse dos grupos hegemônicos.

Para se construir a "agenda de futuro", faz-se necessário um conjunto de medidas estruturais voltadas à regulação de mercado. São exemplos a proteção da entrada de alimentos processados e ultraprocessados nos países, promoção de relações comerciais mais justas com os pequenos produtores de alimentos. Além de medidas regulatórias da publicidade de alimentos, ação que poucos países no mundo conseguiram estabelecer. Recomenda-se que estas medidas sejam estabelecidas não somente em nível nacional, mas também em nível sub-regional, regional e global, utilizando-se dos espaços de entendimento e pactuação dos blocos comerciais e das instâncias e organismos internacionais afetos ao tema.

Uma boa governança global para a nutrição deve necessariamente fortalecer a participação da sociedade civil organizada, dando voz a atores no nível global que antes estavam à margem dos debates internacionais de segurança alimentar e nutricional e estabelecer critérios transparentes com instituições parceiras de forma a evitar conflito de interesses. O SUN foi citado por um grande número de países como uma potencial alternativa para uma governança global mais efetiva da nutrição. Contudo, a sua validade enquanto mecanismo de governança ainda não é estabelecida e o seu desenho e estrutura organizacional não parecem ser apropriados para desempenhar tal função. Com o enfraquecimento do UNSCN como fórum multi-atores e sua 
concentração na função de coordenação das ações de nutrição das agências das Nações Unidas, o fortalecimento da nutrição no âmbito do CSA talvez seja a melhor possibilidade por hora.

A análise de conteúdo dos pronunciamentos dos países por ocasião de uma reunião global do vulto da ICN2 permitiu a identificação das percepções, visões e aspirações que podem levar a uma melhor articulação narrativa que contribua para a construção de uma linguagem e entendimento comuns entre os países rumo à construção de uma efetiva governança global da nutrição.

Reconhece-se, contudo, que o presente estudo apresenta algumas limitações para fornecer esse tipo de subsídio analítico-narrativo. Os pronunciamentos analisados foram de apenas 91 dos 127 países com pronunciamentos disponíveis no website da ICN2. Deixando de fora aqueles de língua francesa, árabe, chinesa e russo. Além do número de países excluídos ser expressivo, incluem-se entre estes alguns que tem peso muito importante na dinâmica global para a nutrição. Outra limitação reside no fato de que os 6 corpus foram organizados segundo região geográfica, o que não necessariamente se traduz em posições homogêneas. Uma complementação à análise realizada seria a organização dos pronunciamentos em corpus segundo alguns critérios pré-estabelecidos relacionados à possibilidade de gerar insights de governança, como por exemplo, fazer ou não parte do SUN. 


\section{Referências Bibliográficas}

1. Organização das Nações Unidas para Alimentação e Agricultura e Organização Mundial da Saúde (FAO/OMS) [homepage na Internet]. Second International Conference on Nutrition (ICN2). [acesso em 27 mar 2015] Documentos. Disponível em: http://www.fao.org/about/meetings/icn2/en/

2. Stedile \& Carvalho. Soberania Alimentar: Uma necessidade dos povos, 2012. [acesso em 6 jul 2015]. Disponivel em: mpabrasil.org

3. Stuckler, D; Nestle, M. Big Food, Food Systems, and Global Health. PLos Medicine series on Big Food that examines the activities and influence of the food and beverage industry in the heath arena. June 2012, Vol 9, Issue 6.

4. Organização Pan-Americana de Saúde (OPAS) Alimentos e bebidas ultraprocessados na América Latina: tendências, efeito sobre a obesidade e implicações para as políticas públicas 2015; Washington, DC.

5. Ribeiro, S. Los que se quieren comer el mundo, 2008. [acesso em 27 ago 2015] Disponível em:Disponível em:

http://www.jornada.unam.mx/2008/12/06/index.php?section=opinion\&article $=029$ a 1 eco

6. Coitinho C. \& Mahy L. The global governance for nutrition - challenges and perspectives, 2014. [no prelo].

7. Recine E \& Beghin N. A Agenda de Nutrição nas Estratégias Internacionais: Iniciativas em Andamento, Desafios e Propostas. Contribuições para 0 debate no Conselho Nacional de Segurança Alimentar e Nutricional. 2014. Disponível em: http://www4.planalto.gov.br/consea/documentos-do-site-queestao-privados/a-agenda-de-nutricao-nas-estrategias-internacionaisiniciativas-em-andamento-desafios-e-propostas-1-1.pdf

8. Organização das Nações Unidas para Alimentação e Agricultura/ Organização Mundial da Saúde (FAO/OMS). Public Interest Civil Society Organizations and Social Movements Forum Declaration to the Second International Conference on Nutrition (ICN2). [acesso em 27 mar 2015] Documentos. Disponível em: FAO/OMS (2014b) http://www.fao.org/3/aat641e.pdf.

9. Fórum para Soberaria Alimentar. 23rd - 27th de Fevereiro de 2007, Nyéléni, 2007. [acesso em 28 jun 2015] Declaração do Fórum para Soberania Alimentar. Disponível em: http://www.nyeleni.org/spip.php?article290

10. Ribeiro N L. Via Campesina, Soberania Alimentar e Agroecologia. Artigo com base no mini-curso "Agronegócio, Campesinato e Soberania Alimentar. Curso ministrado na XIX Semana de Geografia em 2013, no dia 21 de agosto, na FCT/UNESP, Presidente Prudente. Disponível em: 
http://www.reformaagrariaemdados.org.br/sites/default/files/Via\%20Campesi na,\%20soberania\%20alimentar\%20e\%20agroecologia\%20\%20Leandro\%20Nieves\%20Ribeiro,\%202013.pdf

11.Scaling Up Moviment [homepage na Internet]. [Acesso em 9 jul 2015]. Disponível em http://scalingupnutrition.org/about.

12. United Nations Systems Standing Committee on Nutrition [homepage na Internet] [Acesso em 14 jul 15]. Disponível em http://www.unscn.org/

13. Organização das Nações Unidas para Alimentação e Agricultura/ Organização Mundial da Saúde (FAO/OMS). Parliaments for Better Nutrition, Final Statement. Second International Conference on Nutrition (ICN2). [acesso em 27 mar 2015] Documentos. Disponível em: FAO/OMS (2014b) http://www.fao.org/3/a-at641e.pdf.

14. Organização das Nações Unidas para Alimentação e Agricultura/ Organização Mundial da Saúde (FAO/OMS). Conference Outcome Document: Rome Declaration on Nutrition. Second International Conference on Nutrition (ICN2). [acesso em 27 mar 2015] Documentos. Disponível em: FAO/OMS (2014b) http://www.fao.org/3/a-at641e.pdf

15. Organização das Nações Unidas para Alimentação e Agricultura/ Organização Mundial da Saúde (FAO/OMS). Conference Outcome Document: Framework for Action. Second International Conference on Nutrition (ICN2). [acesso em 27 mar 2015] Documentos. Disponível em: FAO/OMS (2014b) http://www.fao.org/3/a-at641e.pdf

16. Minayo CSM. O desafio do conhecimento: pesquisa qualitativa em saúde. 12‥ Edição. São Paulo/Rio de Janeiro: Hucitec - Abrasco;2010.

17. Bardin L. Análise de Conteúdo. Edições 70 LDA/Almedina Brasil; 2004.

18. Popping, Roel. 2004. Computer-assisted Text Analysis. London: Sage.

19. Hohl et al, 2012 The London School of Economics and Political Science. Workshop in Applied Analysis Software MY591. Houghton Street, London WC2AE, 2011-2012.

20. Moreira, A S P, Camargo B V, Nóbrega S M. Perspectivas TeóricoMetodológicas em Representacoes Sociais. Editora Universitária Universidade Federal da Paraíba. João Pessoa, Paraíba, Brasil. 2005.

21. Organização das Nações Unidas (ONU). Informe presentado por el Relator Especial sobre el derecho a la alimentacion, Olivier De Schutter. Informe final: El potencial transformador del derecho a la alimentacion. Consejo de Derechos Humanos. 24 de enero de 2014. 
22. World Health Organization. Connecting global priorities and human health: a state of knowledge review. 2015.

23. Fian International. Windfuhr M; Jonsén J. Food Sovereignty. Towards democracy in localized food systems, 2005.

24. Hawkes C, Chopra M. Friel S (2010) Globalization, Trade, and the Nutrition Transition. In Globalization and Health: Pathways, Evidence and Policy, pp. 235-263 [Labonte R, Schrecker T, Packer C, Runnels V, editors]. Routledge.

25. Moodie R; Stuckler D; Monteiro C; Sheron N; Neal B; Thamarangsi T; Lincoln P; Casswell S. (2013) Profits and Pandemics: prevention of harmful effects of tobacco, alcohol, and ultra-processed food and drink industries. Lancet 381(9867):670-9.

26. Stuckler D \&; Nestle M. Big Food, Food Systems, and Global Health. PLos Medicine series on Big Food that examines the activities and influence of the food and beverage industry in the heath arena. June 2012, Vol 9, Issue 6.

27. Hawkes C. Organização Mundial da Saúde. Marketing Food to Children: Changes in the Global Regulatory Environment; 2004-2006. Disponível em http://www.who.int/dietphysicalactivity/regulatory environment CHawkes07. $\underline{\text { pdf }}$

28. Organização das Nações Unidas para Alimentação e Agricultura. [homepage na Internet]. América Latina e Caribe sem Fome. [acesso em 28 ago 2015] Disponível em: https://www.fao.org.br/vernoticias.asp?id noticia=917

29. Magnusson R. Non-communicable diseases and global health governance: enhancing global processes to improve health development. Globalization and Health, (2007) 3:2 doi: 10.1186/1744-8603-32

30. Hawkes $\mathrm{C}$. The role of foreign direct investment in the nutrition transition. Public Health Nutrition: 8(4), 357-365.

31. Thow AM. Trade liberalization and the nutrition transition: mapping the pathways for public health nutritionists. 2009. Public Health Nutrition: 12(11), 2150-2158.

32. Rayner B; Hawkes C; Lang T; Bello W. Trade liberalization and diet transition: a public health response. 2007. Health Promotion International. Vol 21. No. S1.

33. Associação Brasileira de Saúde Coletiva. [homepage na Internet].110. Congresso Brasileiro de Saúde Coletiva [acesso em 14 ago 15] Disponível em:

http://www.abrasco.org.br/site/2015/08/estado_gestao_publica_saude_abra scao/ 
34.Duncan J \& Barling D, 2012. Renewal through Participation in Global

35. Valente LS. 2015. Towards the full realization of the Human Right to adequate Food and Nutrition.

36. Committee on World Food Security. 36a. sessão. Proposal for na International Food Security and Nutrition Civil Society Mechanims for Relations with CFS, 2010.

37. Conselho Nacional de Segurança Alimentar e Nutricional. Seminário Internacional "Desafios Globais para o Direito Humano à Alimentação, a Soberania e Segurança Alimentar e Nutricional e os papeis do Brasil”. 29 e 30 de outubro de 2012.

38. Monteiro CA, Cannon G. The impact of transnational "Big Food" companies on the South: a view from Brazil, 2012. PLos Med 9(7):e1001252. 
Tabela 01: Estatísticas básicas dos discursos dos países, por regiões.

\begin{tabular}{|r|r|r|r|}
\hline & $\begin{array}{r}\text { Unidade de } \\
\text { Contexto Inicial }\end{array}$ & $\begin{array}{r}\text { Número de } \\
\text { palavras no } \\
\text { corpus }\end{array}$ & $\begin{array}{r}\text { Número de } \\
\text { páginas no } \\
\text { corpus }\end{array}$ \\
\hline África, língua & 24 & 15.116 & 28 \\
inglesa & 3 & 1.722 & 4 \\
\hline $\begin{array}{r}\text { América do } \\
\text { Norte }\end{array}$ & & & 26 \\
\hline América Latina & 17 & 14.465 & 20 \\
\hline Ásia & 20 & 12.658 & 22 \\
\hline Europa & 22 & 14.301 & 6 \\
\hline Oceania & 5 & 3.177 & \\
\hline
\end{tabular}


Tabela 2 - Classes e percentuais de palavras de casa classe com coeficiente phi maior que 0,2 , identificadas nos diferentes corpus

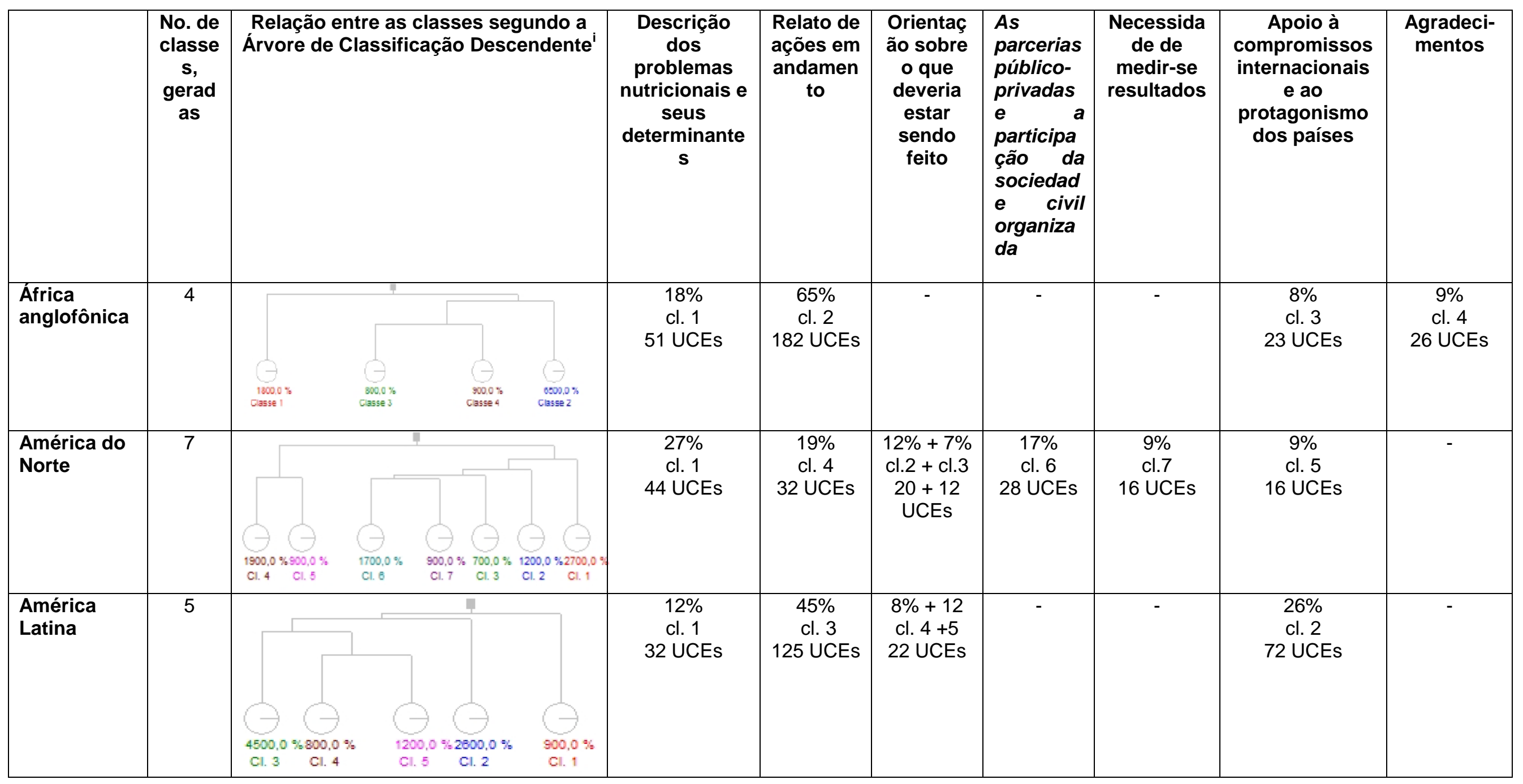




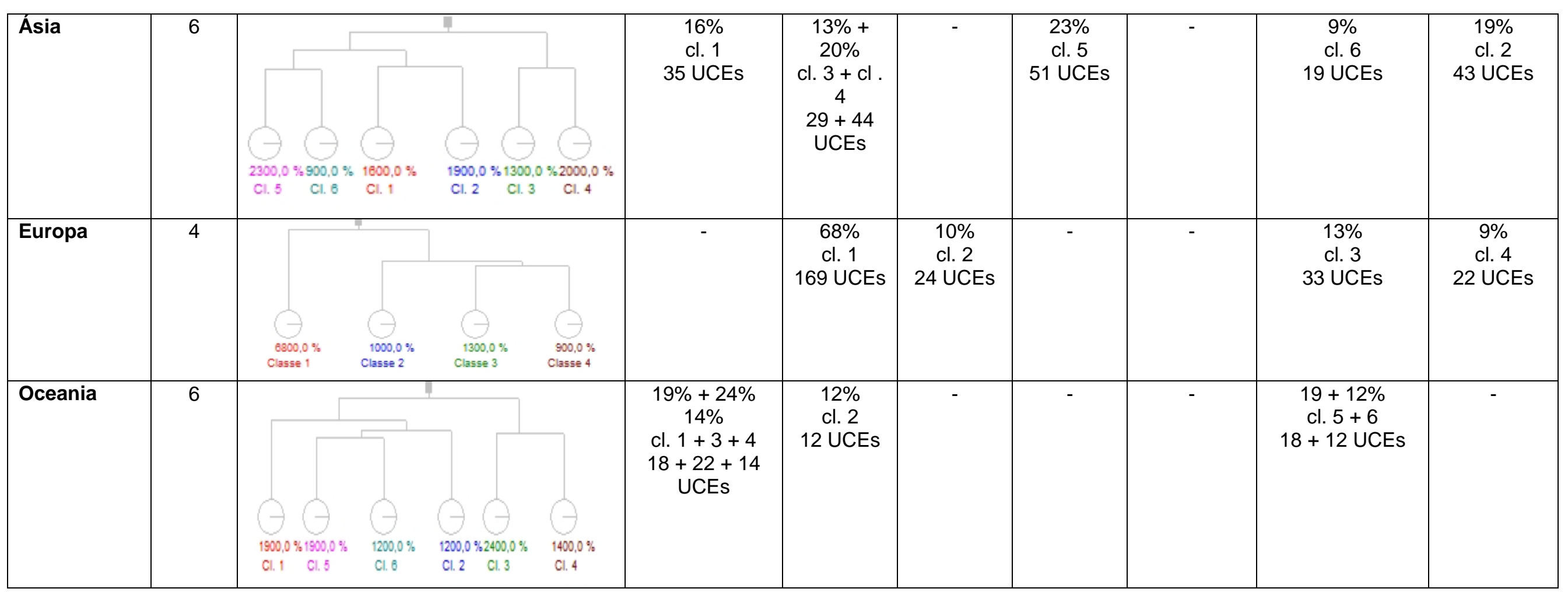


Artigo 2 
Title: Potentials and challenges for a common market put forward the nutritional agenda: the case of Mercosul.

\section{Abstract:}

The South America Common Market (Mercosul). It's a free trade area and net exporting bloc. In the last decades, all Mercosul countries have faced urbanization, industrialization and achieved greater economic integration to global markets. Transnational food companies became dominant actors in the regional food system taking advantage of the different commodities. The bloc is a political place for harmonization and can play a key strategic and political role in putting healthy eating at the center of the global discussions. The study aims identifying challenges and potentials of Mercosul to help addressing the nutrition agenda of the members countries. There are structures that have the political mandate to promote and protect people's health and has the technical capacity to influence the establishment of norms and standards. Areas for potential joint action include regulating the growth of transnational food companies marketshare, regulating foreign direct investments and regulating food advertising. Putting health and the promotion of healthy eating at the center of food trade policy will require the reorientation of development models, strong political commitment and the articulation of public health priorities with other sectors such as agriculture and industry.

Key words: nutrition transition, food trade, obesity, food system, mercosul. 


\section{Introduction:}

Since the 1960s, regional economic integrations have been a goal pursued by most middle-income countries. It allows economies to gain scale and move up the value chain through import substitution industrialization. Integration also allows competition with most advanced exporters ${ }^{1}$.

The regional economic integrations could be organized by trade blocs. This is a type of intergovernmental organization where regional barriers to trade are reduced or eliminated among the participants' states. Nowadays, there are several blocs. The main ones are: European Community (EC), North American Free Trade Agreement (NAFTA), Asia Pacific Economic Cooperation (APEC), Association of Southeast Asia Nations (ASEAN), several sub-blocs of the African Union (AU) and the Common Market of the South (Mercosul), Trade blocs can be stand-alone agreements between several states or part of regional organizations. Depending on the level of economic integration, trade blocs fit into different categories: preferential trade areas, free trade areas, custom unions, common markets or economic and monetary unions.

From an economic growth perspective, there are some potential advantages of trade bloc agreements: (1) Foreign Direct Investment increases that benefits the economies of participating nations; (2) Economics of Scale created by the larger markets; (3) Competition, once the trade blocs brings manufactures in numerous countries closer together; (4) Trade Effects and (5) Market Efficiency ${ }^{1,2}$.

Beyond the regional economic integrations, at the international level, the World Trade Organization (WTO) regulates the world trade policy. The WTO was created in 1994, as a supranational body dedicated to the liberalization of commercial interactions between nations ${ }^{1}$.

Despite these potential economic advantages, trade liberalization and trade bloc agreements heavily influence food trade and can have a negative impact on people's diets, nutritional status and public health ${ }^{3,4}$.

Food trade policies are becoming an important driver for the global food supply. If, on one hand, more and cheaper food is available potentially reducing 
hunger and undernutrition, diets based on local and traditional foods are giving away to rising consumption of energy-dense processed foods, some of which have very high sugar, fat and salt content. These changes in dietary patterns are associated with rising rates of obesity and non-communicable diseases worldwide. Coupled with decreased physical activity, the consequence is the nutrition transition.

The rise of food trade is an important determinant of the nutrition transition, and of the increasing obesity rates worldwide. Some countries initiated the food trade liberalization in the 1980s. But, there was in the 1990s that many countries liberalized the food trade via global, regional, and bilateral agreements. The global value of food trade grew from US\$224 billion in 1972 to US\$ 438 billion in 1998. Food accounts 11 per cent of global trade, a greater proportion than fuel ${ }^{5,6}$.

Reductions in barriers to trade, the growth of transnational food companies, foreign direct investments (FDI) and liberalization of media advertising are examples of how food trade policies are related to nutrition transition and are also affecting the food system ${ }^{7}$. Taking FDI as an example. It has proved particularly important in the spread of highly processed foods ${ }^{3}$. Between 1988 and 1997, food industry FDI increased from US\$ 222 million to US $\$ 3$ billion in Latin America ${ }^{8}$. FDI has stimulated the global spread of supermarkets and processed food.

The purpose of this paper is to systematize and analyse nutrition related structures and work processes within one economic trade bloc, the Common Market of the South (Mercosul), to identify in which extent they have the potential to positively influence the establishment of nutrition sensitive food trade norms and standards or, at least, to produce resistance to those that could lead to the increase of obesity in its member states.

\section{Methods:}

A search of health relates literature was conducted to identify relevant literature (primary through Scielo, PubMed and Google Scholar), using terms as 
"nutrition transition", "food trade", "globalisation", "trade liberalisation", "trade blocs", "obesity", "food system".

Besides, based on the authors' personal experiences in Mercosul technical activities it was also done a deep review about the bloc's functioning and mainly how the food trade regulation is dealt with in Mercosul in order to identify and discuss possibilities to this bloc to play a key strategic and political role in putting healthy diets and nutrition outcomes at the centre of regionalglobal discussions on food systems and trade agreements on a public health perspective.

\section{HOW IS FOOD TRADE REGULATION DEALT WITH IN MERCOSUL?}

In Latin America, the Common Market of the South (Mercosul) is an economic and political agreement among Argentina, Brazil, Paraguay, Uruguay, and Venezuela. The Treaty of Asunción, in order to enable its States Parties to enlarge their domestic markets, making the integration a fundamental pillar to accelerating economic and social development, created Mercosul on March 26, 1991.

The Treaty of Asunción proposed measures to facilitate internal trade among Mercosul countries ${ }^{9}$ and stimulate commercial exchanges with other countries $^{10}$, seeking economic development with social justice ${ }^{11}$. Mercosul is currently characterized as a free trade area and a full customs union.

The establishment of a common market among Mercosul member nations has several goals: (1) to promote the free movement of goods, services and production factors among countries, including the elimination of customs duties and non-tariff restrictions (2) the establishment of a common external tariff and a common trade policy with regard to non member States or groups of States, and the coordination of positions in regional and international economic and commercial forums (3) to coordinate macroeconomic and sectorial policies among States Parties; (4) to commit States Parties to harmonize their legislation in relevant areas in order to strengthen the integration process ${ }^{11}$. 
The decision-making structures of Mercosul have a hierarchical pyramid shape. There are three decision-making bodies: (1) the Common Market Council (CMC) - the highest-level agency with authority to conduct its policies and assure compliance; (2) the Common Market Group (CMG) - the executive body responsible for establishing work plans and negotiating agreements with parties on behalf of Mercosul; (3) the Commission of Commerce of Mercosul (CCM) - a technical body that supports the CMG in commercial issues, to ensure the correct functioning, monitoring and reviewing of issues associated with trade policies ${ }^{11}$.

The Treaty of Asunción structured Mercosul's CMG in ten Sub Working Groups (SWGs) in order to coordinate macroeconomic and sectorial policies ${ }^{11}$. Furthermore, its Article 19 opened the possibility of establishing other SWG if necessary ${ }^{11}$. There are currently 17 SWG. Some of these are related to food trade, food agreements and legislation.

\section{Functioning of Mercosul}

From all Sub Working Groups of the CMG, 2 of them (SWG3 and SWG11) are related to food trade.

\section{a) Sub-Working Group 3 (SWG3): Technical Regulations and Conformity} Assessment

The minimization of technical barriers encountered intra-Mercosul and globally is essential to eliminate differences between countries ${ }^{12}$ and facilitate trade. The SWG3 stands out for being the one facilitating the harmonization of technical regulations, procedures and product standards, including food products, which are being imported and exported within countries of Mercosul and also for other economic blocs. Its main goal is to facilitate integration of production and trade.

SWG3 works in the following areas: harmonize technical regulations and assessment procedures; harmonize systems, structures and national conformity assessment activities; establish conditions for the acceptance of the results of 
the activities of the evaluation systems; promote the integration of national systems and structures of legal metrology ensuring forms of cooperation; develop and evaluate negotiating proposals on "standards, technical regulations and conformity assessment" by Mercosul. National coordinators organize all of these activities ${ }^{13}$.

Each country has a national coordinator and an alternate. Brazil is represented by the National Institute of Metrology, Quality and Technology (INMETRO) of the Ministry of Development, Industry and Foreign Trade. Argentina's coordinator is from the Bureau of Consumer Protection, Ministry of Economy. Paraguay is from Ministry of Industry and Trade; Uruguay from Ministry of Industry and Energy, and Venezuela from Ministry of Trade

\section{b) Committee on Food of SWG3}

Mercosul countries are major producers and exporters of food and therefore there is a significant need for harmonization of technical regulations related to food. The Committee on Food of SWG3 was established since the original structure of Mercosul to play this role. Of a total of 275 Mercosul Technical Regulations (RTM) harmonized under SWG3 about $70 \%$ was the result of work of the Commission on Food ${ }^{14}$.

When standardizing technical requirements there is a need to have it done in accordance with the currently found in international markets ${ }^{12}$. To this aim, the Committee on Food takes advantage of existing international standards and systems, such as World Trade Organization and the Codex Alimentarius ${ }^{14}$.

The WTO Agreements set to ensure that regulations, standards, testing and certification procedures do not create unnecessary obstacles to trade, apply to food quality standards and labelling. The General Agreement on Tariffs and Trade (GATTs) involves the majority of the agreements used to facilitate food trade such as the Technical Barriers to Trade (TBT), the Agreement on Agriculture $(A \circ A)$ and the Agreement on the Application of Sanitary and Phytosanitary Measures (SPS) ${ }^{2}$. 
The SPS which defines how governments can apply food safety and animal and plant health measures has been notably important in food trade, both to help assuring quality, but also to prevent that strict health and safety regulation are used as excuses for protectionist policies. And the article 20 of GATT allows governments to enforce barriers to trade that protect human health and rulings in favour of health protection ${ }^{2,15}$.

The Joint Food and Agriculture Organization (FAO) and World Health Organization (WHO) Codex Alimentarius Commission was established in 1962 to protect health of the consumer and, at the same time, to ensure fair practices in food trade. The Codex Commission develops internationally recognized standards, codes of practice, guidelines and other recommendations relating to foods, food production and food safety.

The Codex Alimentarius is recognized by the World Trade Organization as an international reference for the resolution of disputes concerning food safety and consumer protection. It is also a reference to governments for the preparation and updating of national laws and regulations of food. However, if countries consider that such standards are not as strict as necessary, the countries may lay down more rigid rules.

Both the Codex Alimentarius and the WTO recognize the need for "health protection". However, this "protection" is still restricted to the food safety aspect. It's urgent that nutritional aspects of the foods being traded are also considered in light of the rising of global burden of diet-related chronic diseases.

\section{c) Sub-Working Group 11 - Health (SWG11)}

Unlike the SWG3 the Working Subgroup 11 (SWG11) was not included in the initial structure of Mercosul. It was organized five years later, in $1996{ }^{1}$.

The main goal of the SWG11 is "to harmonize laws and resolutions of the States Parties relating to goods, services, materials and products in the area of Health, the criteria for the epidemiological surveillance and control of health" 16,17. Thus, SWG11 is intended to protect and promote the health of people and 
at the same time, facilitate the exchange of goods and services by reducing barriers to regional trade - seeking to contribute to the integration of the block with full attention and quality ${ }^{18,19}$.

In Brazil, the overall coordination of the SWG11 is under the responsibility of the Ministry of Health ${ }^{20}$ and similar arrangements can be found in the other Mercosul countries. Due to the scope of activities performed by SWG11, it is very important that it maintains close relationships with several other subgroups, including the SWG3.

\section{Putting nutrition before trade - is it possible?}

Obesity is a public health concern in Brazil, as well as in Mercosul countries and also around the world. Table 1 shows the prevalence of obesity and overweight in Mercosul member states.

Humans tend to maximize energy intake and minimize physical activity. They usually appreciate sweet, fatty and salty foods. Mostly these kinds of food are made from processed substances extracted or refined from whole foods (oils, hydrogenated oils and fats, flours and starches, variants of sugar, and cheap part of remnant of animal foods with minimal or no whole foods. They tend to be energy dense and are classified as ultra-processed products ${ }^{26}$, Considering that human biology has not changed over the last centuries, what has changed is the environment within which food choices are made. Swinburn $^{27}$ argues that obesity can be defined as the result of people responding normally to the obesogenic environment they find themselves in.

The evidences suggest that diets have been influenced by three important changes in the food system: (1) the growth of transnational food corporations, driven by trade and foreign direct investments, that increases the availability of processed food; (2) liberalization of international food trade and FDI that makes the food and their price more available; and (3) global food advertising and promotion that shapes the food preferences especially to the more vulnerable public ${ }^{28}$. These factors are related and enhance each other 
making the environment more and more "obesogenic". All of this is happening in Mercosul.

In the last decades, all Mercosul countries have faced a rapid urbanization, globalization and a greater economic integration to global markets. This has led to important lifestyle changes in regards to eating and physical activity. Traditional and healthier eating patterns have been rapidly replaced by globalized practices where ultra-processed products ${ }^{26}$ have a large share of the food basket. These foods are largely and aggressively promoted as "modern" and "convenient".

Industrialized food production, trade, globalization and marketing, contribute, in a great part, for the increasingly obesogenic environment observed in the Mercosul free trade area, where healthy food choices are becoming increasable difficult.

In 2002, the WHO and the WTO prepared a joint report on the public health implications of trade. This document noted that trade agreements do take some account of health, permitting national trade-restrictive measures that protect human health, but only those that are the least trade-restrictive relative to any other measure. The report concluded that "there is common ground between health and trade", but there is also a ground of disputes and conflicts between health and trade. Although the report covered matters as diverse as intellectual property rights, food insecurity, and infectious disease control and food safety, it failed to address and suggest ways to overcome those potential conflicting areas in ways that would be helpful to countries ${ }^{29}$.

In 2004, the WHO member states adopted the Global Strategy on Diet, Physical Activity and Health ${ }^{30}$. Trade policy proved to be one of the most contentious issues during the negotiations suggesting, once again, the need for the international community to take a closer look at trade's impact on nutrition ${ }^{30}$. 
a) The importance of the regulatory actions: the case of nutrition labelling

Given the heavy reliance on international standards for regional harmonization, regional regulations tend to reinforce the status quo to facilitate trade. This is the main challenge that the Committee on Food of Mercosul faces when one or a group of its members put public health nutrition concerns in the discussion.

The harmonization process about nutrition labelling in Mercosul is one example of developing and negotiating "standards, technical regulations and conformity assessment" once health and nutrition priorities were taken as important variables to be considered in the negotiation process.

Worried about the nutritional transition and the rapid rise of obesity, the Brazilian government decided to establish mandatory nutrition labelling to enable consumers to make better-informed food choices and also to stimulate a more balanced nutrition profile of processed foods ${ }^{31}$. The Ministry of Health also decided that the nutritional information should be presented in portions of consumption and not per 100 grams as normally happens ${ }^{32}$. This form of presentation was intended to make the information more accessible to the final consumer.

Codex Alimentarius standards proved to be of no use in this process and a nutrition based methodology was developed and applied to establish the Brazilian portions ${ }^{32}$, that were specific for the national food consumption patterns. It was decided, at the time, that international trade would not be an issue and impediment for the Brazilian regulation that was adopted in 2003.

The new Brazilian regulation led to the need to have Mercosul harmonized regulation on nutrition labelling of packaged foods and portions of packaged food label $\left.\right|^{33,34}$. The countries have developed a long negotiation process so that the public health objectives might lead the decisions.

Later that same year (2003), SWG-3 approved the RTM 04/10 on "declaration of nutritional properties" ${ }^{35}$. Again, this was based primarily on the recognition of the importance of providing truthful and understandable nutrition 
information to the consumer to support healthier food choices. This was an example of both the challenges but also the possibilities of incorporating health and nutrition goals in decisions involving industrial and trade rules and processes.

\section{b) Mercosul Strategy of Nutrition for Health and Food and Nutrition}

\section{Security}

Another example of using a regional trade bloc space to advance the nutrition agenda is Mercosul's Strategy of Nutrition for Health and Food and Nutrition Security. This strategy was created within the SWG11 and adopted in 2009 considering (1) that food and nutrition security is a prerequisite to health promotion and protection and (2) the need of building multisector food and nutrition policies to achieve food and nutrition security ${ }^{36}$. The main goal was to create a political space to discuss, facilitate international cooperation and agree regional positions on issues related to food and nutrition policies. A formal Working Group (WG FNS) and a work plan followed. The WG FNSs meets twice every six months - one face to face and one by videoconference.

Activities are based on six strategic exes: (1) Encouragement of intersectorial actions and the quality of food and nutrition services; (2) Guarantee of food safety and quality; (3) Food and nutrition surveillance; (4) Promotion of healthy eating and healthy practices; (5) Prevention and control of micronutrient deficiencies and (6) Prevention and control of malnutrition (due to deficit or excess) and nutrition related non-communicable diseases ${ }^{36}$.

Outputs of this working group include agreements on regional studies to develop new standards of weigh gain in pregnant women, on micronutrient initiatives and on concerted actions to prevent and control obesity. Despite its importance and huge potential, up to now there is no register of the WG FNS discussing food trade policies towards coordinating positions in regional and international forums/meetings.

There is no direct structural connection or coordination between the Committee on Food of SWG3 and SWG11 but a mechanism such as the 
Mercosul Strategy for Health and Food and Nutrition Security and its derived working group could build that bridge.

In summary, WG FNS, being part of SWG11 has the political mandate to promote and protect people's health and has the technical capacity to influence the establishment of norms and standards in Mercosul by bridging up with the Committee on Food/SWG3. Areas for potential joint action include, among others, regulating the growth of transnational food companies marketshare, regulating foreign direct investments and regulating food advertising. Also, WG FNS could act as an observatory to systematically assess the potential nutritional impact of Mercosul food trade regulation, before they are adopted, to make sure they encourage, and not discourage, the adoption of healthy diets.

\section{Conclusions:}

Putting health and the promotion of healthy eating at the center of food trade policy is deeply challenging and will require the reorientation of development models but is crucial to address the current obesity epidemics and other nutrition challenges. It will require strong political commitment and the articulation of public health priorities with other sectors involved in the food system such as agriculture and industry. In this context food governance is a determinant factor with the understanding that "nutrition sensitive" food trade rules and agreements should be done at multi-level governance of food policy (global, regional, national).

At the global level, the Codex Alimentarius is beginning to take this into consideration but the advances are very slow. It's urgent that the nutrition advocates engage directly and act within international trade agreement's spaces, like WTO, to promote healthy eating. The framework Convention on Tobacco Control (FCTC) provides some valuable lessons of developing a nontrade treaty that sets a pro-health standard in trades disputes. Potential international agreements might cover difficult issues to be handled just on national level, as marketing restriction for unhealthy food products, for example. 
Serious consideration on how this lessons could be applied to nutrition need to take place at the international level.

At the regional level, regional blocs, are strategic spaces for action that should be used. Their member states have the goals of adopting common trade policies, coordinating positions in regional and international economic and commercial forums, coordinating macroeconomic and sectorial policies and harmonizing their legislation in relevant areas in order to strengthen the integration process. The example of Mercosul shows that the bloc approach can be helpful when countries want to work together for adopting more rigid rules and regulations in regards to aspects related to the rising of global burden of diet related to chronic diseases. It also shows that a well-defined and operational working group on Food and Nutritional Security, for example, could fill a strategic and political space for putting healthy diets and nutritional outcomes at the centre of the discussions and decisions on food trade agreements.

And, at the national level, where the most important actions take place, food governance will benefit substantially from these regional and international approaches, that coupled with national supply side measures, can build markets for affordable healthy food. National considerations impact on regional and international decisions, but these decisions also influence and support national decision making processes.

Finally, it's important to be aware of the role of the industry, professional bodies, experts and civil society organisations on monitoring and seeking to put (or not) health and the promotion of healthy eating at the centre of food policy arenas at these multi-levels. 


\section{References:}

1. Foxley A (2010) Regional Trade Blocs. The Way to the Future? Carnegie Endowment for International Peace.

2. World Health Organization (2007) Food Safety and Globalization of Trade in Food. A challenge to the public health sector. Food Safety Unit. Programme of Food Safety and Food Aid. Geneva: WHO.

3. Hawkes C (2005) The role of foreign direct investment in nutrition transition. Public Health Nutrition. 8, 357-365.

4. Rayner G. Hawkes C, Lang T, Bello W (2014) Trade liberalization and the diet transition: a public health response. Health Promotion International. Vol. 21 No. S1 doi: 10.1093/heapro/dal053. Downloaded from http:heapro.oxfordjournals.org/by guest on April 28, 2014.

5. Pinstrup Andersen P, \& Babinard J (2001) Globalization and human nutrition: Opportunities and risks for the poor in developing countries. African Journal of Food and Nutrition Sciences, 1, 9-18.

6. Chopra M, Galbraith S \& Darton-Hill I (2002) A global response to a global problem: The epidemic of overnutrition. Bulletin of the World Health Organization, 80, 952-58.

7. Thow AM \& Hawkes C (2009) The implications of trade liberalization for diet and health: a case study from Central America. Globalization and Health 2009, 5:5 doi:10.1186/1744-8603-5.

8. Food and Agriculture Organization (2004) The State of Food Insecurity in the World 2004: Monitoring progress towards the World Food Summit and Millennium Development Goals. Food and Agriculture Organization. Rome: FAO.

9. Brazil, Minister of External Affairs (2012) Mercosul: Aspectos gerais do Mercosul. Available at http://www.mercosul.gov.br/principais-tema-daagenda-do-mercosul /aspectos-gerais-do-mercosul.

10. Brazil, Mercosul: América do Sul e integração regional. Available at http://www. itamaraty.gov.br/temas/america-do-sul-e-integracaoregional/mercosul.

11. Common Market of the South, MERCOSUL (1991). Tratado de Assunção. 
12. Bezerra CAM, Thiago ECS. (1993) O Mercosul e as normas técnicas. Ciência da Informação. 1993;22(1): 68-70.

13. Common Market of the South, MERCOSUL (2006). GMC/RES NO. 13.

14. Brazil, Minister of Development, Industry and Commerce, Instituto Nacional de Metrologia, Qualidade e Tecnologia - Inmetro. (2012). Articulação internacional. Available at http://www.inmetro.gov.br/ barreirastecnicas/indice.asp.

15. Bloch MG \& Jungmann ER (2007) Health Policy and the World Trade Organization. In Globalization and Health, pp. 250-267 [I Kawachi and S Wamala, editors]. New York: Oxford University Press.

16. Brazil. Minister of Health. (2005). Coordenação Nacional do SGT № 11 "Saúde" Mercosul. Metodologia de Trabalho para o Sub Grupo de Trabalho no 11 "Saúde". Brasília: Mercosul.

17. Machado MH, de Paula AE, Aguiar Filho W. (2007). O trabalho em saúde no Mercosul: uma abordagem brasileira sobre a questão. Cadernos de Saúde Pública. 23(supl. 2):S292-S301.

18. Brasil, Ministério da Saúde (2005) Coordenação Nacional do SGT no 11 "Saúde" Mercosul. Metodologia de Trabalho para o SGT n 11 "Saúde"/Mercosul. Brasília.

19. Sánchez DM (2007) Procesos de integración de salud: una reflexión sobre los desafíos del Mercosur en salud. Cadernos de Saúde Pública. 23(supl.3):S155-S63.

20. Brazil. Minister of Health (2004) A saúde no Mercosul.

21. Ferrante D, Linetzky B, Konfino J, King A, Virgolini M, Laspiur S. (2009) Minister of Health. National Risk Factors Surveillance: evolution of the epidemic of chronic non communicable diseases in Argentina.

22. Brazil, Instituto Brasileiro de Geografia e Estatistica. (2010). Pesquisa de Orcamentos Familiares 2008/2009. Antropometria e Estado Nutricional de Criancas, Adolescentes e Adultos no Brasil. Rio de Janeiro.

23. Paraguay, Ministerio de Salud Publica y Bienestar Social (2011). Primera Encuesta Nacional de Factores de Riesco para Enfermedades no Transmisibles. 
24. Pisabarro P, Gutierrez M, Bermudez C, Prendez D, Recalde A, Chaftare Y, Manfredi A. (2009) Segunda Encuesta Nacional de Sobrepeso y Obesidad (ENSO 2). Rev med. Urug: 25 (1): 14-26, mar.

25. Florez H, Silva E, Fernandez V, Ryder E, Sulbaran T, Campos G, Calmon G, Clavel E, Castillo-Florez S, Goldberg R (2005) Prevalence and risk factors associated with the metabolic syndrome and dyslipidemia in White, Black, Amerindian and Mixed Hispanics in Zulia State, Venezuela. Diabetes Res Clin Pract 69:63-77.

26. Moodie R, Stucler, Monteiro C, Sheron N., Neal B. Thamarangsi T. Lincocoln, Casswell S. (2013) Profits and pandemics: prevention of harmful effects of tocacco, alcohol, and utra-processed food and drink industries. The Lancet. Published online February 12, 2013 http://dx.doi.org/10.1016/S0140-6736(12) 62089-3.

27. Swinburn B, Sacks G, Hall K, Mc Pherson K, Finegood DT, Moodie M, Gortmarker S (2011) The global obesity pandemic: shaped by global drivers and local environment. The Lancet. Vol 378. August 27, 2011.

28. Hawkes C, Chopra M. Friel S (2010) Globalization, Trade, and the Nutrition Transition. In Globalization and Health: Pathways, Evidence and Policy, pp. 235-263 [Labonte R, Schrecker T, Packer C, Runnels V, editors]. Routledge.

29. World Health Organization and World Trade Organization (2002) WTO Agreements \& Public Health. A joint study by WHO and the WTO Secretariat. Geneva: WTO.

30. World Health Organization (2004) Global Strategy on diet, physical activity and health. Available at http://www.who.int/dietphysicalactivity/en/. Geneva: WHO.

31. Brazil. Minister of Health, National Agency of Sanitary Surveillance (2003) Resolucao - RDC no. 360, de 23 de dezembro de 2003: aprova regulamento tecnico sobre rotulagem nutricional de alimentos embalados, tornando obrigatoria a rotulagem nutricional. Diario Oficial Uniao, 26 dez. 2003; Secao 1.

32. Brazil. Minister of Health, National Agency of Sanitary Surveillance (2003) Resolucao - RDC no. 359, de 23 de dezembro de 2003: aprova 
regulamento tecnico de porcoes de alimentos embalados para fins de rotulagem nutricional. Diario Oficial Uniao, 26 dez. 2003; Secao 1.

33. Common Market of the South, MERCOSUL (2003) GMC/Resolucao no. 44/03, de 10 de dezembro de 2003: aprova o regulamento tecnico do Mercosul sobre Rotulagem nutricional de alimentos embalados, LII GMC. Montevideo.

34. Common Market of the South, MERCOSUL (2003) GMC/Resolucao no. 46/03, de 10 de dezembro de 2003: aprova o regulamento tecnico do Mercosul sobre Rotulagem nutricional de alimentos embalados, LII GMC. Montevideo.

35. Common Market of the South, MERCOSUL (2011) Subgrupo de Trabalho oㅜ 3, Comissão de Alimentos. Ata CA oㅜ 04/11.

36. Common Market of the South, MERCOSUL (2009). Mercosul/RMS/Acordo 08/09. 
Table 1 - Prevalence of obesity (body mass index $>30 \mathrm{~kg} / \mathrm{m}^{2}$ ) and overweight (body mass index $25-29,9 \mathrm{~kg} / \mathrm{m}^{2}$ ) among adults in MERCOSUL member states.

\begin{tabular}{lcc} 
Countries & $\begin{array}{c}\text { Obesity } \\
\text { (body mass index }>30 \\
\mathrm{~kg} / \mathrm{m} 2)\end{array}$ & $\begin{array}{c}\text { Overweight } \\
\text { (body mass index 25-29,9 } \\
\mathrm{kg} / \mathrm{m} 2)\end{array}$ \\
\hline Argentina $^{21}$ & $18,0 \%$ & $35,4 \%$ \\
Brazil $^{22}$ & $13,0 \%$ & $35,0 \%$ \\
Paraguay $^{23}$ & 22,8 & \\
Uruguay $^{24}$ & $21,8 \%$ & $35,3 \%$
\end{tabular}


Artigo 3 
Título: O enfrentamento do sobrepeso e obesidade segundo a percepção dos pontos focais de nutrição de países integrantes do Mercosul.

Resumo: O sobrepeso e a obesidade vêm aumentando em todo o mundo, mas a resposta global tem sido fraca e insuficiente. Sua determinação está associada ao consumo crescente de alimentos ultra processados. Blocos regionais, como o Mercosul, exerceram papel importante na desregulação das relações comerciais de alimentos, o que favoreceu a entrada de alimentos ultra processados nos países importadores. O Mercosul é um bloco econômico de livre-comércio e um espaço político-estratégico para decisões conjuntas em inúmeras áreas, incluindo a nutrição. O bloco conta com uma "Estratégia Mercosul de Nutrição para a Saúde e Segurança Alimentar e Nutricional", operacionalizada por meio de um Grupo de Trabalho (GTSAN), que visa a discutir, a facilitar a cooperação internacional e a coordenar posições políticas regionais relacionadas à nutrição. $O$ presente estudo busca explorar em que medida os países, segundo os pontos focais que compõe o GTSAN, compreendem e incorporam nas suas agendas políticas o enfrentamento da obesidade, além de identificar as percepções destes pontos focais sobre 0 papel da do Mercosul e da cooperação internacional neste âmbito. A percepção dos pontos focais do GTSAN Mercosul é positiva, tanto no que diz respeito à incorporação do enfrentamento à obesidade nas agendas políticas nacionais, quanto ao papel da cooperação internacional e do Mercosul. Existe um consenso sobre o fato de que o grupo permitiu e facilitou a troca sistemática de informações e experiências sobre o tema na sub-região. Em alguma medida os processos no âmbito do GTSAN parecem ter favorecido o fortalecimento das iniciativas nacionais e o estabelecimento de acordos interministeriais. Os achados indicam que o GTSAN tem potencial para ser uma instância que contribua efetivamente para o avanço no enfrentamento da obesidade nos países membros.

Palavras-chaves: obesidade, mercosul, cooperação internacional 
Abstract: The prevalences of overweight and obesity are increasing worldwide, but the global responses have been weak and insufficient. The growing consumption of ultra-processed foods was shown to be associated with these increases. Regional economic blocs such as the Mercosur played an important role in deregulating food trade favoring the entry of ultra-processed food in importing markets. Mercosur is a free trade bloc and a political-strategic space for joint decisions in many areas, including in food and nutrition. The bloc has adopted the "Mercosur Nutrition Strategy for Health and Food and Nutrition Security" operationalized through a Working Group (GTSAN) which aims to discuss, facilitate international cooperation and coordinate regional policy positions related to nutrition. This study aims at exploring how the member countries' focal points for GTSAN understand the obesity challenge, how they perceive policies to address the challenge are incorporated into national agendas, and how they see the role and effectiveness of Mercosur and of international cooperation in this area. In general terms, the perceptions of GTSAN Mercosur focal points are positive both in regards to how obesity is placed in national political agendas, and the role of international cooperation and Mercosur. There is a consensus on the group's having enabled and facilitated the systematic exchange of information and experiences. To some extent the processes within the GTSAN seem to have favored the strengthening of national initiatives and the establishment of inter-ministerial agreements. The findings indicate that the GTSAN is potentially an effective instance to contribute to the progress in tackling obesity in member countries.

Keywords: obesity, mercosur, international cooperation 


\section{Introdução}

O sobrepeso e a obesidade vêm aumentando em todo o mundo. Em 2010, pelo menos 2,8 milhões de pessoas morreram em função destas condições $^{1}$. No entanto, a resposta global a este cenário epidemiológico tem sido fraca e insuficiente face à carga de doenças e aos custos que esta impõe aos sistemas de saúde e às populações do mundo. Apesar de algumas experiências bem sucedidas locais, especialmente focadas na população infantil, nenhum país no mundo registrou, nos últimos anos, redução nas taxas de obesidade ${ }^{2}$.

Hawkes et $a \beta^{\beta}$ destacam a gênese ambiental da obesidade e identificam três grandes blocos de determinantes associados ao modo de vida contemporâneo onde o consumo de alimentos ultra processados ${ }^{19}$ é elevado e está em expansão: preferências alimentares moldadas por práticas de promoção comercial agressivas; dificuldades em acessar física e economicamente alimentos saudáveis; dificuldades na preparação de uma alimentação saudável baseada em alimentos in natura.

A relação entre o consumo de alimentos ultra processados e a obesidade está bem estabelecida. Um estudo realizado pela Organização Pan Americana de Saúde (OPAS) com 12 países latino-americanos, compreendendo o período de 2000 a 2009 demonstrou que, a cada aumento de 20 unidades (em quilogramas) em vendas anuais per capita de alimentos ultraprocessados, resultou em um aumento de 0,28 pontos no Índice de Massa Corporal ${ }^{4}$.

Todos estes fatores estão relacionados ao sistema alimentar hegemônico, o qual nunca esteve tão concentrado e controlado por tão poucos. Os treze maiores conglomerados industriais de alimentos do mundo, denominados coletivamente como "Big food", detém $26 \%$ do mercado global, e 100 cadeias de venda direta ao consumidor controlam 40\% do comércio varejista de alimentos ${ }^{5}$. Nas últimas duas décadas os sistemas alimentares tradicionais de diversos países vêm sendo modificados pelos investimentos de conglomerados agro-alimentares transnacionais, pela liberação do comércio de 
alimentos e pelo uso abusivo de diferentes práticas de promoção comercial $4,6,7,8$

A partir da abertura dos mercados na década de 80 , as estruturas que governam as relações comerciais entre países, como a Organização Mundial do Comércio (OMC) e os blocos regionais comerciais, exerceram papel importante na sua (des)regulação em âmbito global, regional e nacional ${ }^{7,8}$. A eliminação de cotas comerciais e a redução de tarifas estão entre as medidas que mais favoreceram a entrada de alimentos ultra processados nos países importadores. Além dos acordos de livre comércio feitos no âmbito global por meio da OMC, incluem-se também aqueles firmados no âmbito regional, por exemplo, do Mercado Comum do Sul (Mercosul) entre outros ${ }^{8}$.

O Mercosul é um bloco econômico e união aduaneira, na qual há livrecomércio intrazona e política comercial comum entre seus membros, sendo também um espaço político-estratégico que tem sido utilizado para a discussão e tomada de posição conjunta sobre diferentes temas que repercutem nas relações comerciais entre blocos, dentre eles o tema de alimentos. Em 2008, foi aprovada pelos ministros da saúde do Paraguai, Uruguai, Brasil e Argentina a "Estratégia Mercosul de Nutrição para a Saúde e Segurança Alimentar e Nutricional" 9 .

Esta Estratégia, que é operacionalizada por meio de um Grupo de Trabalho denominado GTSAN, é vinculada ao Subgrupo de Trabalho de Saúde do Mercosul e visa a discutir, a facilitar a cooperação internacional e a coordenar posições políticas regionais relacionadas à nutrição. Propõe-se a facilitar a melhoria do padrão alimentar, do estado nutricional, da saúde e da qualidade de vida das populações dos países membros ${ }^{9}$. Além disto, propõe-se a contribuir com a cooperação técnica entre os países, por meio do intercâmbio de conhecimentos, da qualificação dos profissionais e do fortalecimento dos serviços de saúde ${ }^{8}$.

Segundo a resolução que a cria, a Estratégia abrange um campo de ação amplo que contempla temas como o estímulo às ações intersetoriais com vistas ao acesso aos alimentos, à garantia da qualidade dos alimentos, à vigilância alimentar e nutricional, à promoção de alimentação saudável, à 
prevenção e ao controle das deficiências nutricionais e prevenção e ao controle das doenças crônicas não transmissíveis ${ }^{9}$. O GTSAN é composto por pontos focais de cada um dos países membros.

O presente estudo tem como objetivo explorar, segundo a percepção dos pontos focais do GTSAN, em que medida os países compreendem e incorporam nas suas agendas políticas o enfrentamento da obesidade. Procura também identificar as percepções sobre o papel do Mercosul e da cooperação internacional em geral para o combate a esse importante problema de saúde pública.

\section{Método}

Trata-se de um estudo com abordagem qualitativa. Foram realizadas três entrevistas semiestruturadas ${ }^{10}$ em abril de 2012 com informantes chaves da Argentina, Brasil e Uruguai, que atuavam, na ocasião da entrevista, como pontos focais da Estratégia Mercosul de Nutrição para Saúde e Segurança Alimentar e Nutricional. O Paraguai estava momentaneamente fora do bloco no período das entrevistas inviabilizando a sua participação no momento das entrevistas.

O número de entrevistas foi reduzido. No entanto, representam o conjunto de países que no momento da pesquisa compunham o bloco subregional. Além disto, os informantes chaves dos países tinham legitimidade de resposta, uma vez que eram os pontos focais, representantes dos respectivos países neste Grupo de Trabalho o qual operacionaliza a Estratégia Mercosul de Nutrição para Saúde e Segurança Alimentar e Nutricional.

As entrevistas abrangeram os seguintes tópicos:

- Excesso de peso como um problema de saúde pública no país;

- Políticas e ações de enfrentamento, abordagens (setoriais ou intersetoriais), atores e papel da cooperação técnica internacional;

- Espaços do Mercosul para discutir obesidade e sua repercussão no planejamento e programação nacionais; 
As entrevistas foram realizadas em espanhol, no caso da Argentina e Uruguai, e em português no caso do Brasil. Tiveram duração aproximada de 50 minutos e foram gravadas com o intuito de se registrar, da forma mais fidedigna possível, as percepções dos informantes-chave. Todas as entrevistas foram degravadas na língua original para a realização das análises.

A análise dos dados foi feita utilizando-se a Análise de Conteúdo ${ }^{11}$. Trata-se de um instrumento de pesquisa empregado para identificar palavraschave, frases e expressões dentro de um texto, ou conjunto de textos, de acordo com o objetivo do estudo. Ela possibilita a identificação de experiências, crenças, valores e pensamentos dos sujeitos e fontes de informação. Esta técnica consiste em buscar "núcleos de sentido".

Para a execução da técnica foram realizados:

(5) Pré-análise, que é a fase da organização do material analisado. É o momento da constituição do "corpus" de análise, ou seja, a degravação das entrevistas com os pontos focais;

(6) Exploração do material, com uma leitura flutuante e destaque das ideias centrais e núcleos/categorias de sentidos das entrevistas;

(7) Tratamento dos resultados, com leituras e releituras do corpus;

(8) Interpretações em função das categorias identificadas;

Adicionalmente foi realizada uma revisão detalhada de documentos oficiais de domínio público dos três países, disponíveis no período entre novembro de 2014 e maio de 2015 nos websites oficiais dos respectivos Ministérios da Saúde dos países e, no caso do Brasil, no website do Ministério do Desenvolvimento Social e Combate à Fome, uma vez que as ações de enfrentamento da obesidade estão reunidas neste lócus.

O projeto foi submetido ao Comitê de Ética em Pesquisa da Faculdade de Ciências da Saúde da Universidade de Brasília. 


\section{Resultados e Discussão}

Os resultados estão apresentados considerando as duas categorias de análise identificadas nas entrevistas dos pontos focais do GTSAN/Mercosul. As entrevistas foram realizadas com profissionais que desempenham um papel eminentemente técnico e suas percepções, em geral, refletem sua vivência cotidiana.

A primeira categoria caracteriza o que está sendo feito no país para a prevenção e controle da obesidade, considerando os aspectos de intersetorialidade e coordenação das ações. Estes aspectos foram agrupados em uma única categoria dada a inter-relação entre eles.

A segunda categoria de análise indica as percepções sobre a importância do Mercosul e da cooperação internacional para enfrentamento da obesidade. Como será detalhado a seguir, há importantes diferenças de percepção entre os países do bloco.

\section{Ações e estratégias de enfrentamento da obesidade em âmbito nacional: intersetoralidade e coordenação.}

O ponto focal do GTSAN para a Argentina referiu a existência de iniciativas pontuais e fragmentadas para o enfrentamento da obesidade no setor saúde em 2012. Mencionou a existência de uma lei nacional promulgada em $2003^{12}$ compartilhada entre a Saúde e o Desenvolvimento Social, para a coordenação das políticas de segurança alimentar e nutricional, apesar de reconhecer as dificuldades do país para que esta agenda fosse tratada de forma intersetorial.

Em 2009, o governo Argentino publicou o documento oficial "Estratégia Nacional para a Prevenção e Controle das Doenças Crônicas não Transmissíveis (DCNT)" na qual está detalhada a organização de uma estrutura de governança intersetorial em nível nacional com o enfoque do enfrentamento da obesidade No próprio documento está descrito que a regulação de produtos alimentícios no nível nacional é insuficiente, mesmo que já se tenha avançado em alguns acordos voluntários com a indústria de 
alimentos e no Mercosul. Esta Estratégia reconhece também a importância da regulação da publicidade de alimentos $^{13}$. Estes aspectos não foram mencionados durante a entrevista.

Mais recentemente, em 2011, e no escopo da Estratégia descrita acima, foi publicada uma resolução pelo Ministério da Saúde da Argentina criando o Programa Nacional de Prevenção das Doenças Cardiovasculares ${ }^{14}$. No que diz respeito à obesidade destacam-se a realização de acordos com a indústria de alimentos para redução de açúcares nos alimentos processados, a regulação da publicidade de alimentos por meio de projeto de lei a ser submetido ao legislativo e a consolidação da rotulagem nutricional com a produção de documentos técnicos e de material de capacitação e comunicação.

No caso brasileiro, segundo o ponto focal para o GTSAN, a obesidade é reconhecida como um problema e aparece no escopo da Política Nacional de Alimentação e Nutrição desde $1999^{15}$. No entanto, ainda segundo o ponto focal, o enfrentamento da obesidade ganhou importância no país com a publicação do Plano de Ações Estratégicas para o Enfrentamento das DCNT no Brasil, 2011 - $2022^{16}$ e da Estratégia Intersetorial de Prevenção e Controle da Obesidade dois anos mais tarde ${ }^{17}$. Esta última foi elaborada no âmbito da Câmara Intersetorial de Seguranca Alimentar e Nutricional (Caisan), em um Comitê Técnico no qual participaram diferentes setores de governo e um representante da sociedade civil do Conselho Nacional de Segurança Alimentar e Nutricional (Consea), além de ter tido a participação da Organização PanAmericana da Saúde no Brasil.

O ponto focal considera que houve avanços no setor saúde que contribuíram para a Estratégia Intersetorial, a exemplo da estruturação da vigilância alimentar e nutricional e a instituição de uma linha de cuidado integral para a prevenção e controle da obesidade.

No caso do Uruguai, segundo o ponto focal para o GTSAN, as doenças crônicas não transmissíveis estão na agenda de governo. Mas, parece faltar um pouco de sensibilidade para os temas de nutrição. 
" estamos desenvolvendo guias de atenção à mánutrição por déficit e por excesso. Os serviços de saúde estão cheios de crianças com sobrepeso, muito mais do que deficiências nutricionais.. Mas, a atenção nutricional não está padronizada..."

Segundo ele, apesar de existir ações em outros setores, como o Ministério do Desenvolvimento Social, as iniciativas estavam focalizadas no setor saúde com pouca articulação intersetorial.

“.. falta um pouco de integralidade nas políticas. Os outros setores precisam ter uma visão mais de saúde..”.

Ainda, segundo o ponto focal, a ação do Ministério do Desenvolvimento Social estava focada no atendimento das populações mais vulneráveis com ênfase no combate à fome, mas sem atenção concomitante à qualidade da alimentação.

Também no que diz respeito às ações do Uruguai, o ponto focal mencionou que estava em tramitação um projeto de lei com recomendações de boas práticas para a implementação de cantinas saudáveis em centros educativos. A lei, de caráter voluntário, foi promulgada dois anos mais tarde e orienta sobre alimentos que podem ser vendidos nos estabelecimentos escolares $^{18}$. Esta lei faz menção ao Programa de Prevenção de DCNT. No entanto, no site oficial do Ministério da Saúde do Uruguai encontram-se poucas informações sobre este Programa ${ }^{19}$.

De acordo com os relatos dos pontos focais de nutrição do Mercosul, os três países, no momento da entrevista em abril de 2012, experimentavam algum processo de elaboração e implementação de ações para o enfrentamento da obesidade. No entanto, a natureza e complexidade destas ações, principalmente no que se refere à intersetorialidade e coordenação, eram bastante diferentes.

A revista Lancet, numa série de artigos científicos sobre obesidade, destacou que apesar de nenhum país ter conseguido reverter a tendência crescente desta mazela, muitos têm aumentado o número de ações, 
estratégias e políticas para a reversão deste problema ${ }^{2}$. Um estudo realizado pela Organização Mundial da Saúde (OMS) em 2010 apontou que 92\% dos 185 países consultados tinham pelo menos uma política, plano ou estratégia para o enfrentamento das DCNT. Em 69\%, havia um enfoque para o sobrepeso e obesidade. No entanto, em apenas $1 / 3$ identificou-se algum grau de implementação e recursos financeiros para as atividades previstas ${ }^{20}$.

O Fundo Internacional para Pesquisa em Câncer no Mundo (World Cancer Research Fund International) por meio de uma plataforma denominada Nourishing, identifica e monitora as ações de enfrentamento da obesidade dos países em três grandes eixos: sistema alimentar; ambiente alimentar e mudança de comportamento. Segundo esta fonte de dados, sessenta países têm ações de comunicação baseadas em guias alimentares. No entanto, somente quatro países têm regulamentação para a publicidade de alimentos nas escolas ${ }^{21}$.

A dificuldade de incorporar ações regulatórias nas agendas políticas dos países é notória no mundo e no Mercosul. Isto, apesar das evidências sobre a sua importância ${ }^{21}$ e da recomendação da Assembleia Mundial da Saúde para reduzir-se o marketing de alimentos direcionado às crianças ${ }^{23}$.

Faz-se importante ressaltar que o tema "medidas regulatórias" pouco apareceu nas entrevistas. Medidas como a regulamentação da publicidade de alimentos, a taxação de alimentos não saudáveis e outras medidas fiscais e a regulação de transações comerciais não foram citadas. A "rotulagem nutricional" foi o único exemplo citado como importante a ser tratado no âmbito do Mercosul. Pelo fato do Mercosul ser um bloco regional de livre-comércio e dado o impacto das relações comerciais no aumento da obesidade ${ }^{4,24}$ chama a atenção a ausência de menção deste tipo de medidas.

Os três pontos focais do GTSAN mencionaram suas respectivas Estratégias Nacionais de Prevenção e Controle de Doenças Crônicas, e com exceção da Argentina, fizeram relação entre estas e as estratégias/ações de controle da obesidade. Em 2011, a reunião de alto nível na Assembleia Geral das Nações Unidas adotou uma Declaração Política para a prevenção e controle de $\mathrm{DCNT}^{25}$. Em 2013, o Plano de Ação Global para Prevenção e 
Controle das DCNT 2013-20 foi adotado pela Organização Mundial da Saúde ${ }^{25}$ com a meta de aumento zero da obesidade em adultos e adolescentes entre 2010 e 2025. Estes processos globais certamente fomentaram a programação nos países estudados.

Uma questão que talvez possa facilitar a intersetorialidade e a coordenação de ações no âmbito do sistema alimentar é a forma de entender a própria obesidade. O Brasil, diferentemente da Argentina e do Uruguai, compreende a obesidade como uma das manifestações da insegurança alimentar e nutricional o que leva ao seu enfrentamento neste âmbito maior. $\mathrm{O}$ próprio documento da Estratégia Intersetorial de Prevenção e Controle da Obesidade $^{17}$ faz vínculo com o Plano Nacional de Segurança Alimentar e Nutricional (2011- 2015) ${ }^{27}$ e com o Plano de Enfrentamento de DCNT ${ }^{15}$. Nos outros dois países, a obesidade não é considerada como um dos desfechos da insegurança alimentar e nutricional.

\section{Percepções sobre o Mercosul e a cooperação internacional}

A percepção sobre a importância do tema obesidade para o Mercosul e sobre a cooperação internacional varia de acordo com o país.

O ponto focal da Argentina considerou que a cooperação internacional funcionava como catalisador de processos nacionais, percebendo a influência das discussões do GTSAN Mercosul na agenda nacional. Citou como exemplos a criação de um plano operativo anual e a contratação de novos recursos humanos para o enfrentamento da obesidade.

O ponto focal do Brasil considerou que a obesidade é um tema com potencial de unir países para uma ação coordenada, uma vez que consistia em um problema comum a todos no Mercosul. No entanto, considerou que parecia faltar pragmatismo nas atividades do grupo. Considerou ainda que os processos internacionais eram muito morosos, com descompasso entre o ritmo do diálogo internacional e a velocidade com que seria necessário mover-se esta agenda no nível nacional. Salientou que o grupo era novo e que ainda estava em uma etapa inicial de trabalho, compartilhando experiências e pontos 
de vista, mas ressaltou que, mesmo assim, o diálogo sobre rotulagem nutricional, na perspectiva da saúde pública, poderia ser mais robusto.

O ponto focal do Uruguai considerou que a cooperação internacional poderia fortalecer as ações de prevenção e controle da obesidade nos países. Destacou que as recomendações de agências das Nações Unidas, como a OMS e o Fundo das Nações Unidas para a Infância (UNICEF), eram fundamentais uma vez que o país muitas vezes não dispunha de pessoal técnico especializado em todas as áreas. No entanto, não apontou ações concretas desdobradas no país em função do GTSAN.

Houve consenso entre os 3 pontos focais sobre a necessidade de melhorar a articulação do GTSAN com outras instâncias de trabalho do Mercosul. O Brasil ressaltou a falta de articulação com o Sub Grupo de Trabalho 3 (SGT3), instância de discussão dos temas e regulamentos técnicos de rotulagem nutricional. Dos três países, o Uruguai foi o único que mencionou uma articulação em nível nacional entre o SGT3 e a Estratégia Mercosul de Nutrição para Saúde e Segurança Alimentar e Nutricional. Considerando que o GTSAN está alocado no Subgrupo de Trabalho sobre Saúde do Mercosul (SWG11) e que este tem como objetivos harmonizar leis e resoluções de Estados Membros para bens e serviços e produtos de saúde além de proteger e promover a saúde das populações, isto, em tese, daria um mandato ao GTSAN para iniciar o diálogo com os grupos mais diretamente relacionados às trocas comerciais entre os países, em nome da promoção e proteção da saúde.

Apesar das manifestações dos pontos focais sobre a dinâmica e sobre as dificuldades de posicionamento da agenda nos níveis decisórios mais elevados, em 2012, após a realização das entrevistas, foi publicado um Acordo Mercosul dos Ministros da Saúde para a cooperação técnica na área de controle da obesidade ${ }^{28}$.

Mais recentemente, em 2015, um segundo Acordo Mercosul de Recomendação de Políticas e Medidas Regulatórias para a Prevenção e Controle da Obesidade foi estabelecido ${ }^{29}$. Este último apresenta um conjunto de compromissos dos Ministros da Saúde para o enfrentamento da obesidade com o enfoque regulatório. São exemplos: a implementação do Código 
Internacional de Comercialização de substitutos do leite materno; a adoção de medidas regulatórias e fiscais buscando aumentar o acesso e consumo de alimentos saudáveis e reduzir os não saudáveis; o aprimoramento da rotulagem nutricional; e a regulamentação de publicidade de alimentos não saudáveis.

Observam-se avanços no GTSAN entre 2012 a 2015 no que diz respeito à focalização das ações. Em 2012, o plano de trabalho do grupo era bastante amplo, orientado pela própria resolução que o criou $^{8}$. Atualmente, segundo as atas de reunião, as atividades estão mais focalizadas, o que pode ter contribuído para a publicação do Acordo específico para obesidade de 2015, que trata especialmente das medidas regulatórias e mais difíceis de serem implementadas nestes países.

\section{Conclusões}

Diante dos achados conclui-se que a percepção dos pontos focais do GTSAN Mercosul é positiva, tanto no que diz respeito a incorporação de pontos de discussão do grupo nas agendas políticas nacionais, quanto ao papel da cooperação internacional e do Mercosul no enfrentamento da obesidade. O grupo permitiu e facilitou a troca sistemática de informações e experiências sobre o tema na sub-região. Em alguma medida, e considerando as enormes dificuldades de enfrentar este importante problema de saúde publica, os processos no âmbito do GTSAN têm favorecido o fortalecimento das iniciativas nacionais.

O enfrentamento da obesidade deve estar pautado no fortalecimento de políticas intersetoriais coordenadas ao longo do sistema alimentar, garantindo que os governos tenham soberania nas suas decisões e que estes estejam protegidos dos interesses comerciais dos conglomerados transnacionais. É fundamental que os países adotem abordagens que garantam a oferta de alimentos saudáveis produzidos de maneira sustentável por pequenos produtores, a exemplo da agricultura familiar e camponesa, e que estruturem sistemas curtos de abastecimento aproximando os produtores e consumidores. 
Faz-se necessário ainda, o estabelecimento de medidas como a regulação da publicidade de alimentos, o aprimoramento da rotulagem nutricional e as medidas de regulação de mercado como as que desincentivam a entrada de alimentos ultraprocessados nos países importadores e aumentem impostos sobre alimentos não saudáveis.

Desta forma, considerando os fatores determinantes da obesidade e os interesses econômicos dos conglomerados transnacionais de alimentos, que acabam por ter o domínio e o controle dos sistemas alimentares dos países, as políticas e ações regulatórias citadas são contra hegemônicas. Isso dificulta enormemente a sua implementação nos países, dificultando sobremaneira os avanços. Os acordos recentes entre os Ministros da Saúde do Mercosul, são promissores e mostram que este grupo econômico é um espaço politicoestratégico potencialmente importante para o avanço no enfrentamento da obesidade.

O principal desafio que se coloca, entretanto, é implementar as medidas previstas no acordo recente. Apesar de fundamentais, são bastante audaciosas considerando-se os interesses econômicos envolvidos. O posicionamento forte e coletivo dos países do Mercosul para a promoção e proteção da saúde das suas populações, pode favorecer a implementação de tais medidas. 


\section{Referências Bibliográficas}

1. World Health Organization (WHO). Global status report on noncommunicable diseases, 2010. [acesso em 03 jun 15] disponível em: http://www.who.int/nmh/publications/ncd report2010/en/

2. Roberto C, Swinburn B, Hawkes C, Huang T, Costa S, Asche, et al. Patchy progress on obesity prevention: emerging examples, entrenched barriers, and new thinking The Lancet 2015; Vol 385 Jun 13.

3. Hawkes C, Smith T, Jewell J, Wardle J, Hammond R, Friel S et al. Smart food policies for obesity prevention. The Lancet 2015; Vol 385 Jun 13.

4. Organização Pan-Americana de Saúde (OPAS) Alimentos e bebidas ultraprocessados na América Latina: tendências, efeito sobre a obesidade e implicações para as políticas públicas 2015; Washington, DC.

5. Ribeiro, S. Los que se quieren comer el mundo, 2008. Disponível em: http://www.jornada.unam.mx/2008/12/06/index.php?section=opinion\&arti $\underline{\text { cle }=029 \mathrm{a} 1 \mathrm{eco}}$

6. Stuckler D \& Nestle M. Big Food, Food Systems, and Global Health. PLOS Medicine 2012; June 2012, Vol 9, issue 6.

7. Magnusson R. Non-communicable diseases and global health governance: enhancing global processes to improve health development. Globalization and Health, (2007) 3:2 doi: 10.1186/1744-8603-32

8. Hawkes C, Chopra M. Friel S (2010) Globalization, Trade, and the Nutrition Transition. In Globalization and Health: Pathways, Evidence and Policy, pp. 235-263 [Labonte R, Schrecker T, Packer C, Runnels V, editors]. Routledge.

9. Mercosul/RMS/Acordo no. 08/09. Estratégia Mercosul de Nutrição para a Saúde e Segurança Alimentar e Nutricional, 2009.

10. Minayo CSM. O desafio do conhecimento: pesquisa qualitativa em saúde. 12a ${ }^{\mathrm{a}}$. Edição. São Paulo/Rio de Janeiro: Hucitec - Abrasco; 2010.

11. Bardin L. Análise de Conteúdo. Edições 70 LDA/Almedina Brasil; 2004. 
12. Argentina. Lei 25.724. Programa de Nutrição e Alimentação Nacional. Criação do Programa citado, destinado a cobrir os requisitos nutricionais de crianças até 14 anos, mulheres grávidas, descapacitados e idosos em situação de pobreza. [lei na internet] [acesso em 13mai 2015]. Disponível

em http://200.5.235.239/defenpo3/def3/legislacion/leyes/textos/25724txt.htm

13. Ministério da Saúde da Argentina. Resolução 1083/2009 do Ministério da Saúde que aprova a Estratégia Nacional para a Prevenção e Controle das Doenças não Transmissíveis e o Plano Nacional Argentina Saudável, 2009. Disponível em: http://www.infoleg.gov.ar/infolegInternet/anexos/180000184999/183411/norma.htm

14. Ministério da Saúde da Argentina. Resolução 801/ 2011 do Ministério da Saúde que cria o Programa Nacional de Prevenção das Enfermidades Cardiovasculares. Disponível em: http://www.msal.gob.ar/ent/images/stories/insitucional/pdf/resolucion1083-2009-estrategia-nacional-para-la-prevencion-y-control-deenfermedades-no-transmisibles.pdf

15. Ministério da Saúde do Brasil. Política Nacional de Alimentação e Nutrição, 1‥ Edição, 1999.

16. Ministério da Saúde do Brasil. Plano de Ações Estratégicas para o enfrentamento das Doenças Crônicas não transmissíveis no Brasil 20112011. http://bvsms.saude.gov.br/bvs/publicacoes/plano acoes enfrent dcnt 2 $\underline{011 . p d f}$

17. Câmara Interministerial de Segurança Alimentar e Nutricional. Estratégia Intersetorial de Prevenção e Controle da Obesidade: orientando sobre modos de vida e alimentação adequada e saudável para a população brasileira, 2014 [acesso em 12 jun 15]. Disponível em: http://www.mds.gov.br/segurancaalimentar/educacao-alimentar-enutricional/Estrat,PC3,PA9gia,P20Intersetorial,P20de,P20Preven,PC3,P A7,PC3,PA3o,P20e,P20Controle,P20da,P20Obesidade.pdf.pagespeed.C e.MSfETitOrx.pdf

18. Uruguay. Lei. No. 19.140. Alimentação Saudável nos centros de ensino. Normas para sua promoção. Disponível em: http://www.msp.gub.uy/sites/default/files/archivos adjuntos/leyalimentaci onuruguay 19140.pdf 
19. Ministério da Saúde Pública do Uruguay. Programa Nacional de Nutricion (http://www.msp.gub.uy/programas/ciclos-de-vida/programanacional-de-nutrici\%C3\%B3n) Acessado em: 09 fev 2015

20. Organização Mundial da Saúde (OMS). Assessing National Capacity for the Prevention and Control of Noncommunicable diseases. Report of the 2010 Global Survey, 2010b.

21. Nourishing framework [homepage na internet]. Policy framework [acesso em 15 ago 2015]. Disponível em http: www.wcrf.org

22. Hawkes C. Organização Mundial da Saúde. Marketing Food to Children: Changes in the Global Regulatory Environment; 2004-2006. Disponível em

http://www.who.int/dietphysicalactivity/regulatory environment CHawkes $\underline{07 . p d f}$

23. Assembleia Mundial da Saúde (WHA). 63.14. Publicidade para Alimentos e bebidas não alcoólicas para crianças. 63ª. Sessão da Assembleia Mundial da Saúde, 2010.

24. Thow AM \& Hawkes C (2009) The implications of trade liberalization for diet and health: a case study from Central America. Globalization and Health 2009, 5:5 doi:10.1186/1744-8603-5.

25. Assembleia Geral das Nações Unidas. Declaração Política de reunião de alto nível da Assembleia Geral para a Prevenção e Controle das Doenças Crônicas não Transmissíveis, 2011.

26. Organização Mundial da Saúde (OMS). Global action plan for the prevention and control of NCDs 2013-2020. Disponível em:

http://www.who.int/nmh/publications/ncd-action-plan/en/

27. Câmara Intersetorial de Segurança Alimentar e Nutricional. Plano de Segurança Alimentar e Nutricional, 2012-2015. Disponível em: http://www.mds.gov.br/segurancaalimentar/LIVRO_PLANO_NACIONAL_ CAISAN_FINAL.pdf.pagespeed.ce.NSQXeyLv0S.pdf

28. Mercosul/RMS/Acordo no. 08/12. Desenvolvimento de um Projeto de Cooperação Técnica para a Prevenção da Obesidade entre os Estados Partes do Mercosul, 2012. 
29. Mercosul/RMS/Acordo no. 03/15. Recomendação de Políticas e Medidas Regulatórias para a Prevenção e Controle da Obesidade, 2015. 


\section{Conclusões Finais}

Diante dos achados desta pesquisa, conclui-se que, apesar das limitações apontadas no estudo exploratório dos pronunciamentos dos países por ocasião do ICN2, observa-se que de uma forma geral, estes estão, em maior ou em menor grau, programando-se e enfrentando a má nutrição seja caracterizado por carências, déficits e excessos nutricionais das populações, embora com reconhecimento apenas parcial da sua determinação.

São poucas as indicações de medidas dirigidas ao remodelamento dos sistemas alimentares. Estas demandam o enfrentamento com os interesses econômicos das indústrias de alimentos transnacionais que estão no centro do processo de determinação da forma como as populações do mundo se alimentam atualmente.

Para o remodelamento estrutural dos sistemas alimentares, faz-se necessário um conjunto de medidas, entre as quais assumem particular importância aquelas voltadas à regulação de mercado. Estas se dariam tanto para facilitar o acesso a alimentos saudáveis para a população como, por exemplo, promover relações comerciais mais justas com pequenos produtores. Ainda, medidas para proteção da alimentação saudável como iniciativas que dificultem a entrada de alimentos ultra processados em mercados importadores e as medidas regulatórias de publicidade de alimentos em diversos ambientes, como escolas, TV e outras mídias.

Os achados da pesquisa exploratória dos pronunciamentos permitem afirmar que alguns países não apenas reconhecem a importância das ações que coíbem a publicidade de alimentos, mas que estes também têm clareza sobre as dificuldades de colocá-las em prática, apontando alguns caminhos para acumular apoio político a estas medidas, por exemplo, com a articulação com a rede de parlamentares sensíveis ao tema em níveis regional e/ou global.

Sabe-se que a concepção e a implementação de ações e políticas nacionais de segurança alimentar e nutricional são, em alguma medida, balizadas pela estrutura de forças, interesses, características e limitações das estruturas de governança multiníveis. 
Os achados do estudo exploratório global indicam que o SUN aparece, por parte de algumas regiões, como uma possível alternativa de estrutura de governança global de nutrição. No entanto, diante destas manifestações, há que se aprofundar a análise das críticas em relação aos seus processos decisórios que incluem o setor privado; às situações de potenciais conflitos de interesses já identificadas; e sobre o quanto o movimento aprofunda as iniquidades nos processos políticos e decisórios que envolvem esta agenda, entre outras.

Finalmente, o estudo exploratório dos pronunciamentos trouxe à tona também outros elementos chaves que precisam ser considerados para a reestruturação da governança global da nutrição, como o estabelecimento de parâmetros claros para as relações público privadas a fim de identificar, manejar e coibir conflitos de interesses. Aqui vale destacar que a Organização Mundial da Saúde está elaborando um código de conduta para reger essas relações. Este processo, e eventualmente o seu produto, poderão servir de exemplo e estímulo a processos regionais e nacionais com o mesmo propósito.

Em alguma medida, o olhar para o Mercosul por meio dos dois estudos realizados, o primeiro baseado em análise documental e o segundo baseado na análise de percepções dos pontos focais dos países para o GTSAN, ilustram algumas reflexões sobre caminhos a serem trilhados para a governança global para nutrição em espaços sub-regionais.

No que diz respeito ao estudo de base documental (Potenciais e desafios para o mercado comum impulsionar a agenda de nutrição: um caso do Mercosul), ressalta-se a importância do uso estratégico de espaços institucionais globais como o Códex Alimentarius (CA) e Organização Mundial do Comércio (OMC), e regionais/sub-regionais, como os blocos comerciais tipo Mercosul para o enfrentamento da obesidade.

O $C A$, por exemplo, é um programa global que define parâmetros técnicos de qualidade e identidade de produtos alimentares, que servem de base para a definição de legislação específica dos países, facilitando a harmonização internacional de forma a minimizar barreiras sanitárias nas trocas comerciais de alimentos. Já a OMC, vem a ser um organismo 
multilateral onde são definidas e acordadas as regras para as relações comerciais internacionais. Estes são dois espaços internacionais que precisam priorizar a saúde e a promoção da alimentação saudável por meio de medidas como o estabelecimento de regras sanitárias que não respondam somente à segurança do alimento do ponto de vista biológico, mas também no ponto de vista da qualidade nutricional, no caso do CA. E, o estabelecimento de regras as quais incentivassem a importação de alimentos saudáveis, minimamente processados por meio de remoção ou inclusão de tributos, no caso da OMC. Medidas desta natureza são bastante desafiadoras. Para isto é necessário um forte compromisso político dos países e cobrança por parte da sociedade civil organizada no nível global. Em nível regional, os países que compõe blocos comerciais, como o Mercosul, caso articulados em torno de uma mesma agenda e prioridades, podem vir a tornar-se atores estratégicos nestes espaços globais, com vistas a impulsionarem temas que coloquem a saúde e a promoção da alimentação adequada e saudável, como parâmetros fundamentais para a definição de políticas comerciais.

Por sua vez, o estudo baseado na análise das percepções dos pontos focais dos países para o do GTSAN Mercosul, identificou que os processos estabelecidos no âmbito desse grupo de trabalho parecem ter favorecido o fortalecimento das iniciativas nacionais dos países participantes e influenciado o estabelecimento de acordos ministeriais para a prevenção da obesidade. Esta constatação reforça a conclusão anterior sobre a importância dos blocos comerciais regionais para a tomada de posições conjuntas em espaços de negociação global.

Estes avanços observados no âmbito do Mercosul, mesmo que modestos, podem ser considerados como um acúmulo que, a médio prazo, poderá criar as condições necessárias para que medidas mais complexas, como a regulação de mercado, sejam efetivamente implementadas sob a égide da proteção e a promoção da alimentação adequada e saudável.

As perspectivas e desafios para a estruturação de processos ágeis e assertivos devem considerar, em primeiro lugar, a determinação dos problemas nutricionais. A "agenda de futuro" está na implementação de medidas de 
regulação de mercado para o efetivo remodelamento dos sistemas alimentares com o aproveitamento dos espaços regionais e globais para fortalecer movimentos e posicionamentos de países. Os blocos comerciais regionais podem ser espaços estratégicos para a tomada de posições conjuntas em espaços de negociação global. Ainda no que diz respeito às medidas de regulação de mercado, faz-se necessário fomentar processos para a colocada da saúde e promoção da alimentação saudável no centro da agenda. O estabelecimento de regras claras para firmar qualquer tipo de parcerias com o intuito de evitar conflitos de interesse e privilegiar processos decisórios democráticos e participativos, são também elementos centrais. 


\section{Referências Bibliográficas}

CHONCHOL J A Soberania Alimentar. São Paulo, Estudos Avançados, V.19, n. 55, set./dez. Disponível em: <http versão impressa ISSN 0://www.scielo.php?script=sciartext\&pid=S01340142005000300003\&1ng=pt\&nr m=isso> (acesso em: 15/04/2015), 2005.

COITINHO C. \& MAHY L. The global governance for nutrition - challenges and perspectives [no prelo], 2014. .

COMITÉ DE SEGURANÇA ALIMENTAR (CSA). [homepage na Internet]. Home page [acesso em 27 ago 2015] Disponível em: http://www.fao.org/cfs/cfshome/en/

CONSELHO ECONÔMICO E SOCIAL DAS NAÇÕES UNIDAS (ECOSOC). Arrangements institutionnles concernant la nutrition. Abril, 1976.

CONSELHO ECONÔMICO E SOCIAL DAS NAÇÕES UNIDAS (ECOSOC). Institutional Arragements Related to Nutrition. Abril, 1977.

FÓRUM PARA SOBERARIA ALIMENTAR. 23rd - 27th de Fevereiro de 2007. Nyéléni, 2007. [acesso em 28 jun 2015] Declaração do Fórum para Soberania Alimentar. Disponível em: http://www.nyeleni.org/spip.php?article290, 2007.

HURREL A. Sociedade Internacional e Governança Global. Lua Nova no. 4699.

LONGHURST R. Global Leadership for Nutrition: The UN's Standing Committee on Nutrition (SCN) and its contribution. Discussion Paper Volume 2010 Number 390 Acesso em: https://www.ids.ac.uk/files/dmfile/dp390.pdf

MAGNUSSON R. Non-communicable diseases and global health governance: enhancing global processes to improve health development. Globalization and Health, 3:2 doi: 10.1186/1744-8603-32, 2007.

MALDONADO, N. The World Bank's Envolving Concepto of Good Governance and its Impacto $n$ Human Rights. Doctoral workshop on development and international organizations, 2010.

MERCOSUL/RMS/ACORDO NO. 08/09. Estratégia Mercosul de Nutrição para a Saúde e Segurança Alimentar e Nutricional, 2009.

MINAYO CSM. O desafio do conhecimento: pesquisa qualitativa em saúde. 12a . Edição. São Paulo/Rio de Janeiro: Hucitec - Abrasco; 2010. 
ORGANIZAÇÃO DAS NAÇÕES UNIDAS PARA ALIMENTAÇÃO E AGRICULTURA E ORGANIZAÇÃO MUNDIAL DA SAÚDE (FAO/OMS) [homepage na Internet]. Second International Conference on Nutrition (ICN2). [acesso em 27 mar 2015] Documentos. Disponível em: http://www.fao.org/about/meetings/icn2/en/

ORGANIZAÇÃO PAN-AMERICANA DE SAÚDE (OPAS) Alimentos e bebidas ultraprocessados na América Latina: tendências, efeito sobre a obesidade e implicações para as políticas públicas; Washington, DC, 2015.

RECINE E \& BEGHIN N. A Agenda de Nutrição nas Estratégias Internacionais: Iniciativas em Andamento, Desafios e Propostas. Contribuições para o debate no Conselho Nacional de Segurança Alimentar e Nutricional. Disponível em: http://www4.planalto.gov.br/consea/documentos-do-site-que-estao-privados/aagenda-de-nutricao-nas-estrategias-internacionais-iniciativas-em-andamentodesafios-e-propostas-1-1.pdf, 2014.

RIBEIRO, S. Los que se quieren comer el mundo. [acesso em 27 ago 2015] Disponível em:Disponível em: http://www.jornada.unam.mx/2008/12/06/index.php?section=opinion\&article=02 9a1eco, 2008.

RIBEIRO N L. Via Campesina, Soberania Alimentar e Agroecologia. Artigo com base no mini-curso "Agronegócio, Campesinato e Soberania Alimentar. Curso ministrado na XIX Semana de Geografia, no dia 21 de agosto, na FCT/UNESP, Presidente Prudente. Disponível em: http://www.reformaagrariaemdados.org.br/sites/default/files/Via\%20Campesina, \%20soberania\%20alimentar\%20e\%20agroecologia\%20\%20Leandro\%20Nieves\%20Ribeiro,\%202013.pdf, 2013.

SCALING UP MOVIMENT [homepage na Internet]. [Acesso em 9 jul 2015]. Disponível em http://scalingupnutrition.org/about.

STEDILE \& CARVALHO. Soberania Alimentar: Uma necessidade dos povos. [acesso em 6 jul 2015]. Disponível em: mpabrasil.org , 2012.

STUCKLER, D; NESTLE, M. Big Food, Food Systems, and Global Health. PLos Medicine series on Big Food that examines the activities and influence of the food and beverage industry in the heath arena. June, Vol 9, Issue 6, 2012.

UNITED NATIONS SYSTEMS STANDING COMMITTEE ON NUTRITION [homepage na Internet] [Acesso em 14 jul 15]. Disponível em http://www.unscn.org/ 
Anexo 


\section{Nível sub-regional, Mercosul.}

\section{Roteiro para entrevista dos pontos focais do GTSAN}

(1) Qual a prevalência de sobrepeso e obesidade no (país)? O aumento de peso é reconhecido politicamente como um problema de saúde pública? Ha políticas públicas e/ou ações que vem sendo realizadas para o enfrentamento desta situação? Se sim, estas políticas/ações são setoriais (saúde) ou abrangem outros setores de governo? Desde quando o (pais) iniciou a idealização e implementação de políticas e ações voltadas para a prevenção e controle de obesidade? Quem são os atores deste processo e o contexto politico.

(2) Em sua opinião as ações de prevenção e controle da obesidade poderiam ser fortalecidas no nível nacional com apoio de cooperação técnica internacional? Se sim, como? Se não, por quê?

(3) O GT SAN MERCOSUL foi iniciado formalmente em 2009 e tem na sua pauta a discussão de uma ampla agenda de $A \& N$. Em sua opinião, a agenda da prevenção e controle da obesidade deveria ser uma prioridade neste GT ?

(4) Além do GT SAN, há outros grupos de trabalho que discutem temas relacionados a agenda de alimentação e nutrição. Como por exemplo, o Grupo de Trabalho que discute normas técnicas para rotulagem nutricional e também o Grupo de Trabalho para DCNT. Como você analisa a relação entre estes Grupos? Há ou deveria haver algum nível de coordenação ou interlocução entre eles?

(5) Havendo uma recomendação/decisão sobre Alimentação e Nutrição no âmbito do Mercosul - como esta recomendação/decisão é internalizada em seus pais ? Qual é o procedimento? Há algo formalizado? Esta internalização é monitorada tanto no âmbito do MERCOSUL (por exemplo, sendo discutido no GT/instância que o gerou) e também pelo setor nacional responsável pela agenda? 
(6) Você acredita que de alguma forma ou em algum grau as discussões sobre a agenda de prevenção e controle da obesidade no MERCOSUL podem contribuir/afetar a agenda no nível nacional? Por favor, me conte qual e a sua opinião? 